\title{
Extreme ultraviolet spectral irradiance measurements since 1946
}

\author{
G. Schmidtke \\ Fraunhofer Institute for Physical Measurement Techniques IPM, Heidenhofstrasse 8, 79110 Freiburg, Germany \\ Correspondence to: G. Schmidtke (gerhard.schmidtke@ipm.fraunhofer.de; gerhard.schmidtke@ @-online.de)
}

Received: 25 July 2014 - Revised: 5 February 2015 - Accepted: 10 February 2015 - Published: 18 March 2015

\begin{abstract}
In the physics of the upper atmosphere the solar extreme ultraviolet (EUV) radiation plays a dominant role controlling most of the thermospheric/ionospheric (T/I) processes. Since this part of the solar spectrum is absorbed in the thermosphere, platforms to measure the EUV fluxes became only available with the development of rockets reaching altitude levels exceeding $80 \mathrm{~km}$. With the availability of V2 rockets used in space research, recording of EUV spectra started in 1946 using photographic films. The development of pointing devices to accurately orient the spectrographs toward the sun initiated intense activities in solar-terrestrial research. The application of photoelectric recording technology enabled the scientists placing EUV spectrometers aboard satellites observing qualitatively strong variability of the solar EUV irradiance on short-, medium-, and longterm scales. However, as more measurements were performed more radiometric EUV data diverged due to the inherent degradation of the EUV instruments with time. Also, continuous recording of the EUV energy input to the T/I system was not achieved. It is only at the end of the last century that there was progress made in solving the serious problem of degradation enabling to monitore solar EUV fluxes with sufficient radiometric accuracy. The data sets available allow composing the data available to the first set of EUV data covering a period of 11 years for the first time. Based on the sophisticated instrumentation verified in space, future EUV measurements of the solar spectral irradiance (SSI) are promising accuracy levels of about $5 \%$ and less. With added low-cost equipment, real-time measurements will allow providing data needed in ionospheric modeling, e.g., for correcting propagation delays of navigation signals from space to earth. Adding EUV airglow and auroral emission monitoring by airglow cameras, the impact of space weather on the terrestrial T/I system can be studied with a spectral terrestrial irradiance camera (STI-Cam) and also be used investigating real-time space weather effects and deriving more detailed correction procedures for the evaluation of Global Navigation Satellite System (GNSS) signals. Progress in physics goes with achieving higher accuracy in measurements. This review historically guides the reader on the ways of exploring the impact of the variable solar radiation in the extreme ultraviolet spectral region on our upper atmosphere in the altitude regime from 80 to $1000 \mathrm{~km}$.
\end{abstract}

\section{Historical background}

The possibility to transmit radio wave signals from point 1 to point 2 (Fig. 1) "over the horizon" postulates the existence of a plasma layer consisting of free electrons and ions - the ionosphere. The plasma reflects the signals at altitudes between 100 and $300 \mathrm{~km}$ depending on the radio wave frequency. Since the reflectivity of the ionosphere is controlled by diurnal, seasonal and long-term periods, and that it also depends on geographical latitude position, it became clear that the sun is the primary driver. However, the solar radia- tion reaching earth could not explain the generation of free electrons within the upper atmosphere because the photons of a black body at temperature levels of up to $6000 \mathrm{~K}$ correspond to photons with average energies of just $0.52 \mathrm{eV}$ at about $2400 \mathrm{~nm}$. However, the detachment of electrons from molecular nitrogen and oxygen requires photon energies of at minimum $16 \mathrm{eV}$ at $\approx 79 \mathrm{~nm}$ and $12 \mathrm{eV}$ at $\approx 103 \mathrm{~nm}$, respectively. Having this in mind, Saha (1937) and Kiepenheuer (1945) proposed an "ultraviolet excess factor" of up to $10^{6}$ with respect to the solar photospheric intensity to find a pro- 


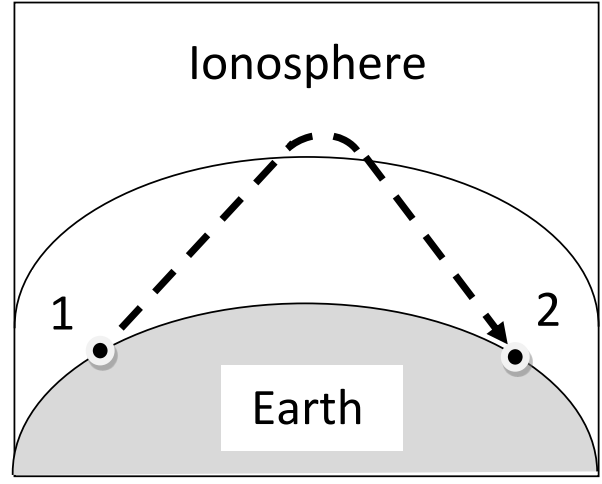

Figure 1. Radio wave signals from a radio transmitter at point 1 are reflected in the ionosphere and can be detected at point 2 "behind the horizon" at point 1 .

duction term possibly explaining the ionospheric densities as revealed by the ionospheric sounding experiments from ground. In the spectral region of interest the solar flux was estimated at an energy level of $0.1 \mathrm{~mW} \mathrm{~m}^{-2}$.

Radio signal transmission became an important subject of intense exploration and scientific research also for several applications in civil and military fields. In this context investigators developed UV spectrographs with photographic film and artificial light sources recording the violet to ultraviolet regions beyond the visible (VIS) sunlight spectrum. These techniques also allowed recording the solar radiation in the ultraviolet spectral region. The spectral UV regions are subdivided in UV-A (380-315 nm), UV-B (315-280 nm), and UV-C (280-200 nm) due to the different biological impacts. Because the UV radiation is absorbed at normal air conditions, investigation of the UV-C requires the application of vacuum equipment. Erich Regener as well as his son Victor H. Regener used balloons as a platform for their UV spectrographs to reach atmospheric regions of lower gas pressures. At altitude levels of up to $33 \mathrm{~km}$ (Regener, 1932) the solar spectrum was recorded from the VIS to the UV-C regions.

A strong impetus for further investigations resulted from the requests to study the solar radiation and their impacts on the parameters of the upper atmosphere for increasing the targeted precision of the rockets A4 (known as V2). During the 1942-1945 period, Erich Regener was responsible for the development of the "Regener-Tonne" or "Regener Barrel" (Regener, 1942) containing an UV spectrograph for recording the solar spectrum, a barograph, a thermograph, an ion recorder, an interferometer to determine the air density, and a galvanometer. It should have been a scientific payload for the first rocket mission through the upper atmosphere up to $50 \mathrm{~km}$ to be recovered by a parachute. In January 1945 a successful flight was carried out with a dummy barrel. The scientific payload could not be launched anymore because of the turbulence from the ending Second World War.

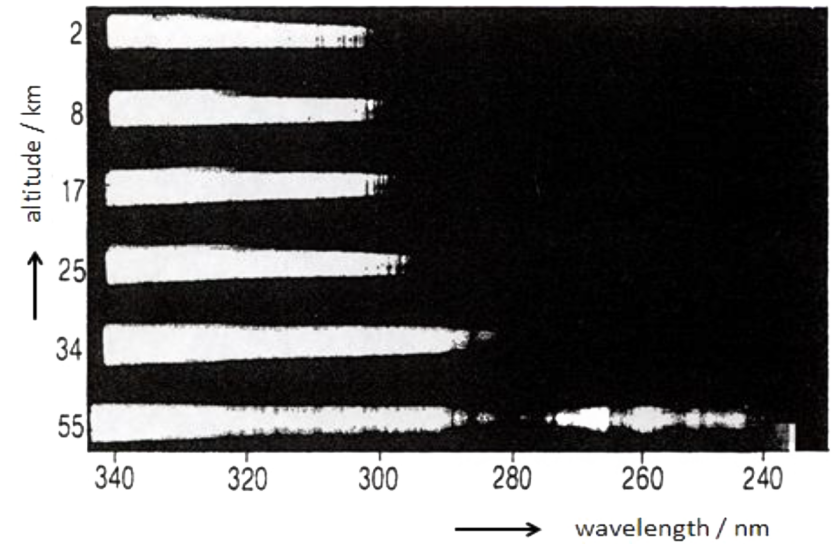

Figure 2. First recording of an ultraviolet spectrum on 10 October 1946 by R. Tousey (Baum et al., 1946; copyright permission granted by the American Physical Society).

After the Second World War space research became one of the great fields of science all over the world with the investigation of the spectral solar irradiance (SSI) in the ultraviolet and extreme ultraviolet (EUV) spectral regions due to the broad fields of applications in thermospheric/ionospheric (T/I) science: in radio communication, in orbit prediction for space crafts and space vehicles, in space technology, in space weather research, and in evaluation of signals from global navigation satellite systems (GNSS).

In the past, EUV/UV SSI data and modeling were reviewed in several publications (White, 1977; Schmidtke, 1984; Rottman, 1987; Lean, 1987, 1991, 1997; Meier, 1991; Tobiska, 1993; Pap et al., 1994; Woods et al., 2004).

In this presentation the history of solar, airglow, and auroral EUV measurements is summarized and updated primarily in view of solar-terrestrial relations.

\section{EUV SSI measurements during the 20th century}

The capture of more than a 100 German V2 rockets by the United States of America provided the possibility to start the first space program after the Second World War. In addition to military tests some of the missiles transported scientific payloads exploring the upper atmosphere and the solar radiation. The first spectrographic recording based on a rocket mission is shown in Fig. 2.

The V2 rocket reached an altitude level of $160 \mathrm{~km}$ recording solar spectra at an exposure cycle of $3.6 \mathrm{~s}$ on a UVsensitized Eastman $35 \mathrm{~nm}$ film. The progressive extension of the solar spectrum into the UV with altitude reflects the decreasing absorption of the solar flux by ozone at altitude levels of $55 \mathrm{~km}$. Spectra above $55 \mathrm{~km}$ were impeded due to the failing pointing of the rocket axis with respect to the sun.

The first successful rocket mission with a solar pointing device is reported by Pietenpol et al. (1953) of the University of Boulder, CO, USA (1953). On 12 December 1952 


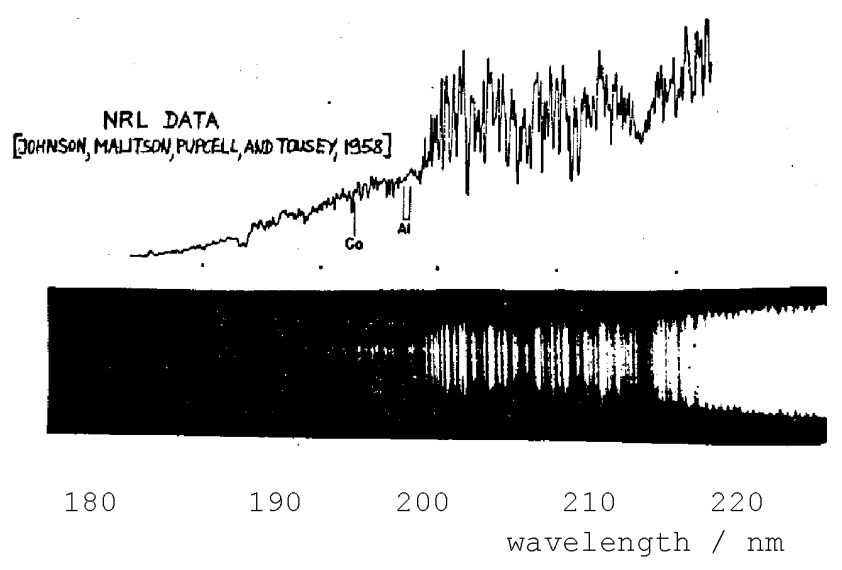

Figure 3. Solar emissions from the photosphere and the transition to the lower chromosphere (Johnson et al., 1958; CAAS, reproduced with permission): densitometric record (upper part) and photographic spectrogram (lower part).

a grazing incident spectrograph aboard an Aerobee rocket recorded the solar radiation in a spectral interval around the hydrogen Lyman- $\alpha$ emission at $121.57 \mathrm{~nm}$ on a photographic film for the first time. After this great success more data were recorded on film in the spectral ranges from 240 to $14.823 \mathrm{~nm}$ (Figs. 3-6; see Tousey, 1963, Hinteregger, 1961a, and Schweizer and Schmidtke, 1971).

Since the solar flux is most intense in the visible spectral region where the detecting photographic film material is also sensitive, double dispersion spectrographs had to be developed in order to suppress the stray light from the VIS in the UV (Tousey, 1963). There are other disadvantages of using film material as detectors. Among them there are the low dynamic range of less than 2 orders of magnitude with a linear response, the relatively long period for generating signals, and the principal difficulties to recover the film for the laboratory evaluation. The latter point hinders the use of this technique in satellites.

Below $50 \mathrm{~nm}$ it is extremely difficult to record solar emission spectra with open slits of the spectrophotometer on film because the SSI in the VIS is exceeding the one in the EUV by more than 6 orders of magnitude. Applying the technique of diffraction filters (Schmidtke, 1968) a spectral recording on film was achieved (Schweizer and Schmidtke, 1971; Schmidtke and Schweizer, 1972) covering the XUV (extreme ultraviolet with the soft X-ray region included) from a $14823 \mathrm{~nm}$ emission of nickel Ni XI to a $21134 \mathrm{~nm}$ emission of iron Fe XIV with a spectral resolution $<5$ p.m. Strong emission lines of iron are presented in Fig. 6.

The spectrophotometer consists of a diffraction filter passing the XUV radiation (Fig. 7). The filter is blocking more than 6 orders of magnitude of the VIS (Fig. 8).

A typical diffraction triple slit filter of $7 \mu \mathrm{m}$ width is used as entrance slit in the X-ray Spectrometer-Spectrograph Tele-

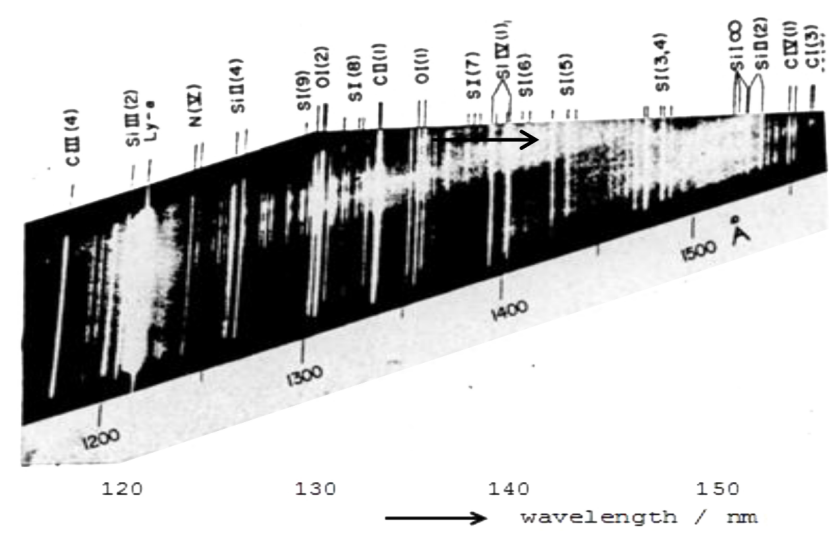

Figure 4. Photographic recording of solar chromospheric EUV spectra (Detwiler et al., 1961; copyright permission granted by the Société Royale des Sciences de Liège).

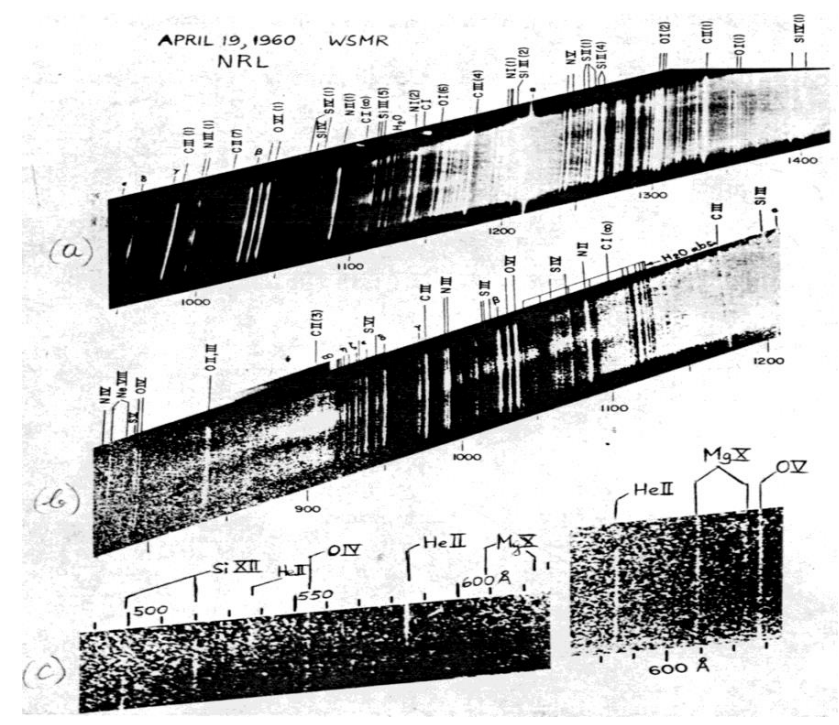

Figure 5. Photographic Spectrograms in the EUV spectral region 140-50 nm (Detwiler, Purcell, and Tousey, 1961; copyright permission granted by the Société Royale des Sciences de Liège): (a) $60 \mathrm{~s}$ exposure, (b) $60 \mathrm{~s}$ exposure, (c) short wavelength sections of same exposure as (b), produced by first-order predispersion (right) and second-order predispersion (left), respectively (Tousey, 1963; copyright permission granted by Springer)

scope (Bruner et al., 1979), decreasing the stray light background of the photoelectric detector significantly.

The technological progress made in photoelectric recording marked a breakthrough in the field of EUV space research. Within a short period of time photographic recordings almost disappeared. Fig. 9 is demonstrates the advantages of the photoelectric technique by an intercomparison with densitometer records. The application of the photoelectric technique (Bendix resistance strip magnetic electron multiplier; Heroux and Hinteregger, 1960) initiated systematic rocket measurements providing the possibility to elaborate a tab- 


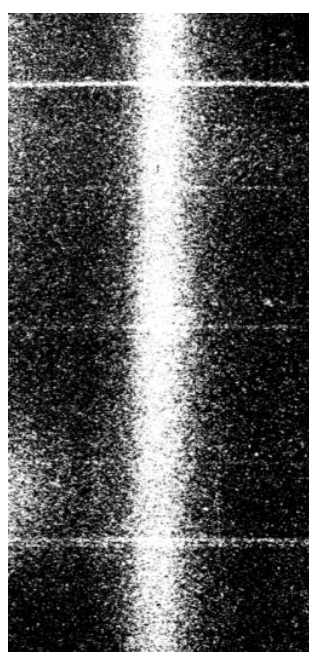

\section{$\leftarrow 18.042 \mathrm{~nm}$ Fe XI $\leftarrow 18.219 \mathrm{~nm}$ Fe XI $\longleftarrow 18.456 \mathrm{~nm}$ FeX}

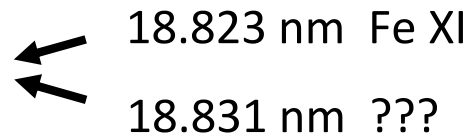

Figure 6. An excerpt of the solar XUV spectrum with iron Fe X and Fe XI emissions recorded on 29 April 1971 (Schweizer and Schmidtke, 1971; (CAAS, reproduced with permission).

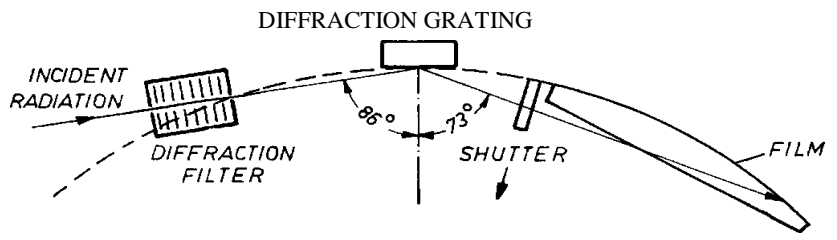

Figure 7. Arrangement of the spectrophotometer recording the solar XUV radiation as presented in Fig. 6 (Schweizer and Schmidtke, 1971; CAAS, reproduced with permission).

ulation of solar UV/EUV fluxes of the spectral range from 1775 to $1 \mathrm{~nm}$ plus total absorption and ionization cross sections (Hinteregger et al., 1965). This tabulation was broadly used as "EUV standard flux" in the science community for many years.

Using the new technique, Hinteregger et al. (1964) and other groups recorded spectra from UV to XUV spectral regions down to $1 \mathrm{~nm}$. At this time many groups worked on solar UV/EUV/XUV research in the industrialized nations all over the world. Examples are presented in Figs. 10 and 11 (Sawyer et al., 1963).

Typical measuring periods during rocket missions of up to 5 min allow for several repetitions of spectral recordings such that absorption profiles are derived with altitude. Using absorption cross sections as determined in the laboratory density profiles of the neutral atmospheric constituents (Fig. 12), scale heights, thermospheric temperatures, and primary and secondary photoionization rates are computed (Hinteregger et al., 1965).

The quantification of the total and ionization cross sections of molecular oxygen and nitrogen in the table published by Hinteregger et al. (1965) pointed to the problem of "radiation hardening" calling for implementing "effective" cross

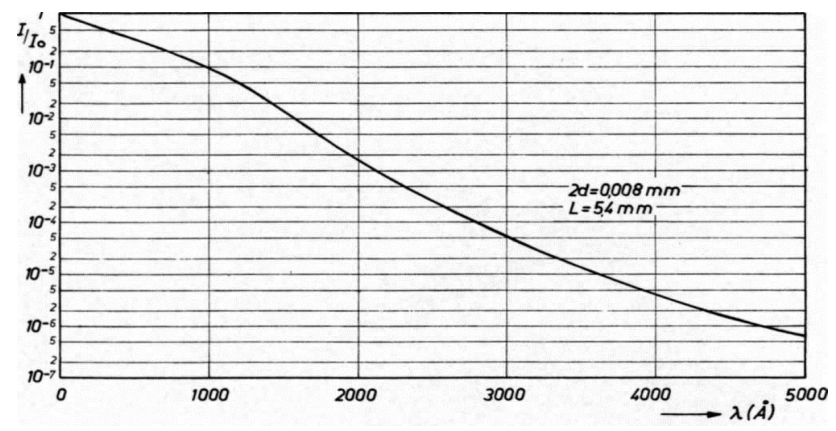

Figure 8. Filter transmission of the arrangement of multiple slits (Fig. 7) with slit width of $8 \mu \mathrm{m}$ and total length of the diffraction filter of $54 \mathrm{~mm}$ (Schweizer and Schmidtke, 1971; CAAS, reproduced with permission).

(a)
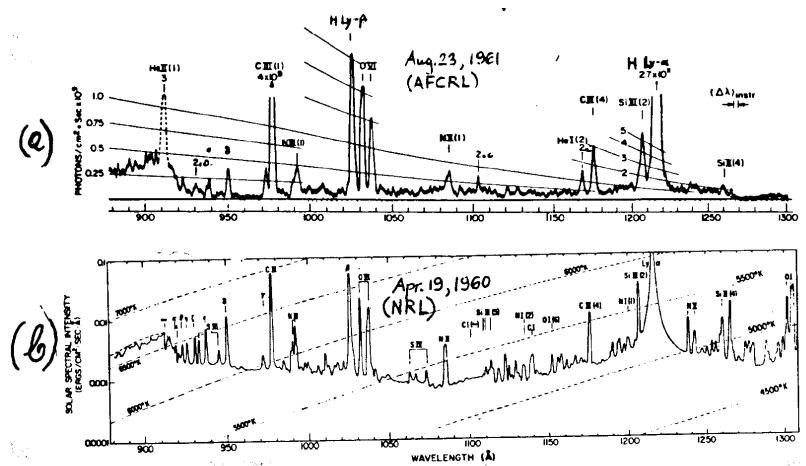

(c)
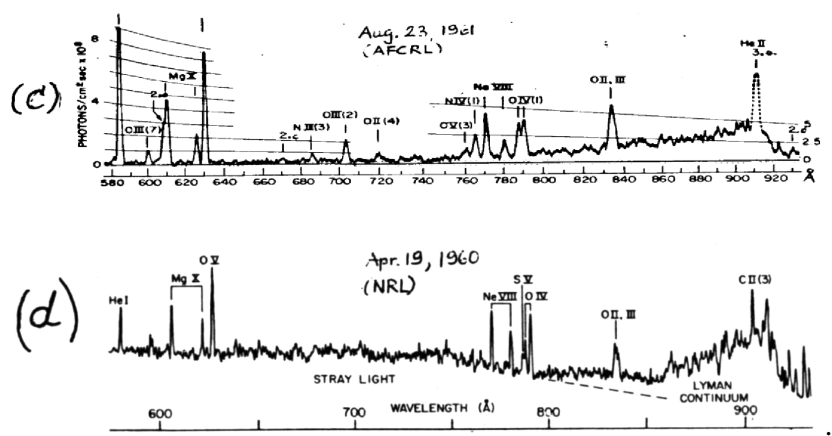

Figure 9. An intercomparison of photoelectric recordings with photographical densitometer records of solar emissions in the EUV spectral region from 130 to $58 \mathrm{~nm}$ (Tousey, 1963, copyright permission granted by Springer; Hinteregger, 1961b, copyright permission granted by the Société Royale des Sciences de Liège)

sections of solar EUV emission lines. This applies to solar emissions with their center of the line width not matching the center of the vibrational absorption feature of oxygen and nitrogen molecules (Schmidtke, 2000a) as it occurs in the EUV spectral region $>60 \mathrm{~nm}$. On its way from space to earth the fraction of EUV radiation closest to the vibrational absorption features is absorbed first at higher altitude levels. The remaining photons are absorbed with cross sections continuously decreasing with lower altitudes, apparently, like "hard" 


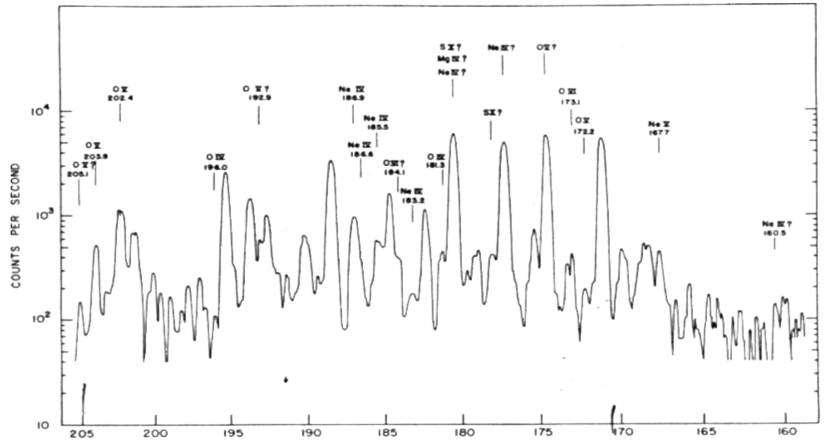

Figure 10. Photoelectric recording of solar flux from 205 to $160 \AA$, 20.5-16.0 nm (Hinteregger et al., 1964; CAAS, reproduced with permission).

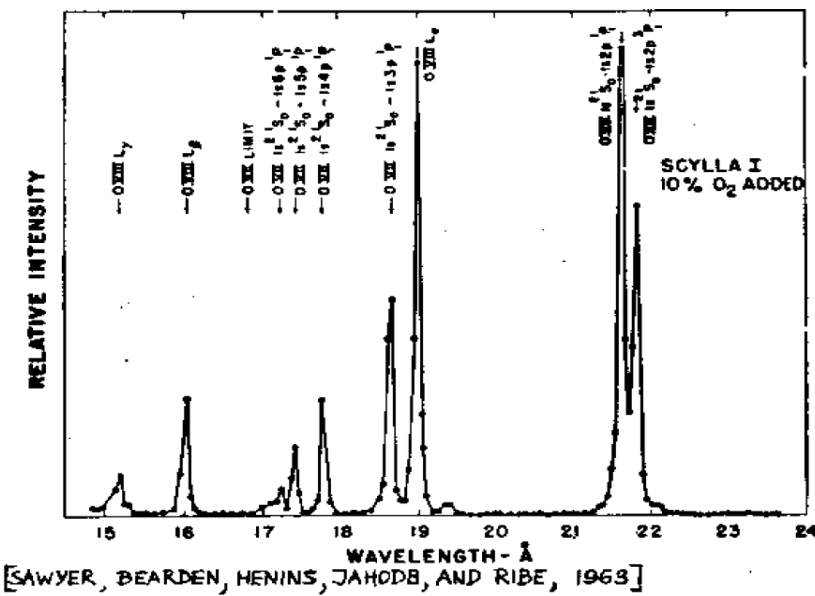

Figure 11. Laboratory spectrum in the XUV region from 2.4$1.5 \mathrm{~nm}$ (Sawyer et al., 1963; copyright permission granted by the American Physical Society).

radiation. Based on this effect the absorbed solar energy is deposited in different altitude regions during solar cycle minimum and maximum conditions due to the induced thermospheric composition changes.

The photoelectric detection technique enabled the development and implementation of EUV spectrometers aboard satellites extending the mission periods from the order of $5 \mathrm{~min}$ to years. Neupert et al. (1964) reported variability of the solar EUV radiation as measured during the mission of the OSO (Orbiting Solar Observatory)-1 satellite. Solar output changes are also noted during the missions of OSO-4 and 5. However, it is very difficult to derive SSI data from those recordings. With the missions of Atmospheric Explorer (AE)-C and E and AEROS-A and B it became evident that optical components are strongly degrading with respect to the efficiency converting EUV photons into electrical signals in the laboratory and even stronger in space. In order to separate solar variability from instrumental changes, strong efforts started in the laboratory based on different strategies such

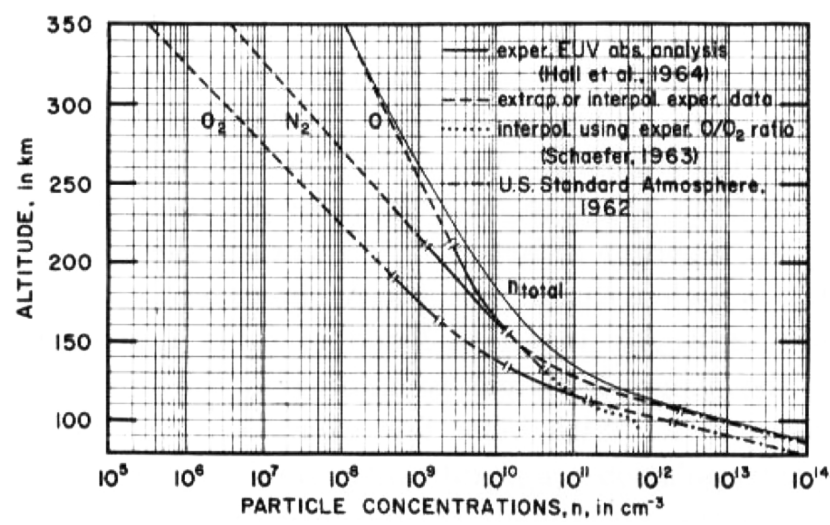

Figure 12. Neutral density profiles of molecular and atomic oxygen and of molecular nitrogen are computed from sequential EUV spectral recordings during a rocket mission (reprinted from Hinteregger et al., 1965; copyright permission granted by Elsevier publishing).

as firing "calibration rockets" (Woods and Rottman, 1990) to cross-calibrate satellite instruments, preselecting more stable optical components, and adding a radioactive source to trace efficiency changes of the EUV detector (Schmidtke et al., 1974). Count rates (Fig. 13a) generated by $64 \mathrm{keV} \beta$ particles from a nickel 63 radioactive source with 92 years half-life show large efficiency changes of the detector during the AEROS-A mission (Schmidtke et al., 1975). There is a strong correlation with instrumental temperature variability (Fig. 13b) of a few degrees. Degradation with increasing accumulated count rates of the multiplier superpose the temperature effect.

Worden et al. (1996) published a more detailed analysis on the degradation in the Airglow-Solar Spectrometer Instrument (ASSI) during the mission aboard San Marco 5 satellite (Schmidtke et al., 1985). In Fig. 14a efficiency changes with time and with wavelength of 1 channel, out of 18 channels, are presented for the San Marco 5 mission period of about 9 months. Degradation refers to decreasing and increasing efficiency.

Figure 14b degradation shows dramatic individual features for five different channels in the Airglow-Solar Spectrometer Instrument while recording the same solar emission $\mathrm{H}$ Lyman- $\alpha$ at $121.57 \mathrm{~nm}$ during the same period.

The ASSI aboard the spinning satellite San Marco 5 (Schmidtke et al., 1985) measured equatorial airglow emissions and solar radiation in the spectral interval from 20 to $700 \mathrm{~nm}$ by four spectrometers with 18 overlapping channels. Every $10 \mathrm{~s}$ one solar spectrum and several airglow spectra were recorded. In order to record strong solar emissions and faint terrestrial airglow spectra with the same instrument, dynamic ranges of up to $1: 10^{13}$ in the visible spectrum are realized. Based on a calibration rocket of the University of Colorado, Boulder, flown on 10 November 1988, a solar EUV irradiance reference spectrum is derived (Schmidtke et al., 1992). ASSI data are also included in a study comparing with 
(a)
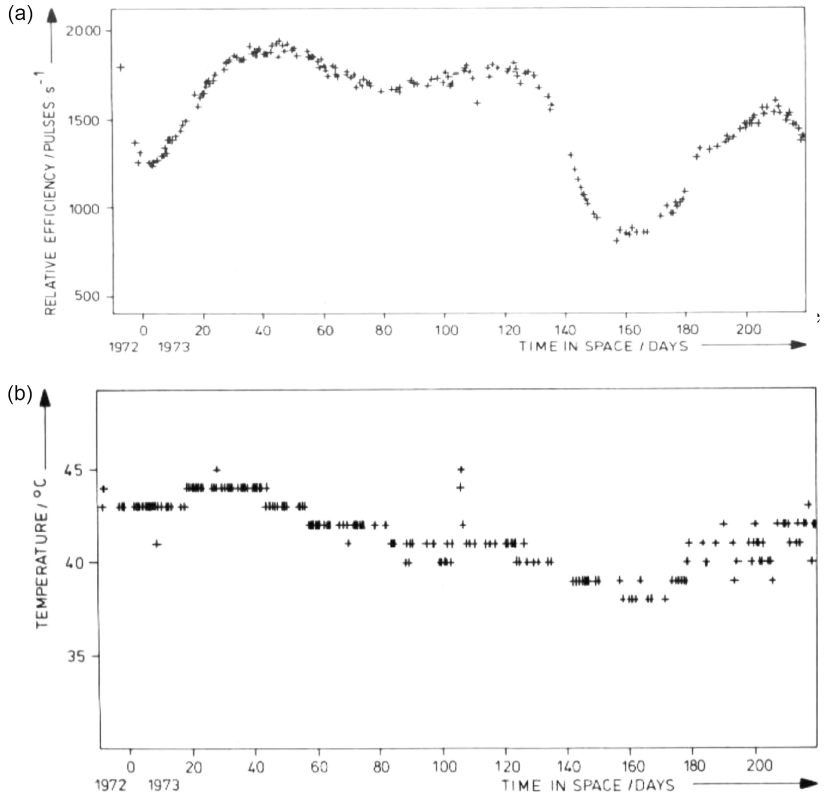

Figure 13. (a) Count rate changes of a Bendix MEM 306 multiplier using a nickel 63 radioactive $\beta$ source (reprinted from Schmidtke et al., 1975; OSA copyright permission). (b) Trace of the temperature changes during the mission of AEROS-A to be compared with the count rate changes during the same time in Fig. 13a (reprinted from Schmidtke et al., 1975; OSA copyright permission).

modeled and other measured EUV data in the spectral range of EUV data from 4 to $105 \mathrm{~nm}$ (Tobiska et al., 1993).

The results from the Student Nitric Oxide Explorer (SNOE) initiated a critical review on the accuracy of SSI in the EUV region (Solomon et al., 2001). SNOE data showed strong evidence that the standard flux at that time (Hinteregger et al., 1981) should be increased by a factor of 4 (!) below $25 \mathrm{~nm}$ (Fig. 15). These results supported suggestions for increasing solar EUV fluxes published by Richards and Torr (1984) and by Siskind and al. (1990).

With the publication of SNOE results it became evident that the fundamental problem of EUV spectroscopy in space was not solved at that time, namely, the determination of the individual pace of degradation for each wavelength with time (see Figs. 13 and 14). Too many resources are still to be consumed for estimating the efficiency changes of each measurement. The COSPAR (Committee on Space Research) task force with the topic "Inter-comparison/compilation of relevant solar flux data related to aeronomy" (Delaboudinière et al., 1978), in cooperation with 31 scientists, did point to this problem already. During many subsequent workshops exclusively dealing with this topic the inherent difficulties related to degradation/aging became partially understood: each point of the optical components such as optical gratings, mirrors, detectors, etc., shows different optical properties with respect to efficiency and its changes with time. The history of the efficiency for each point starts with the fabrication processing, (a)

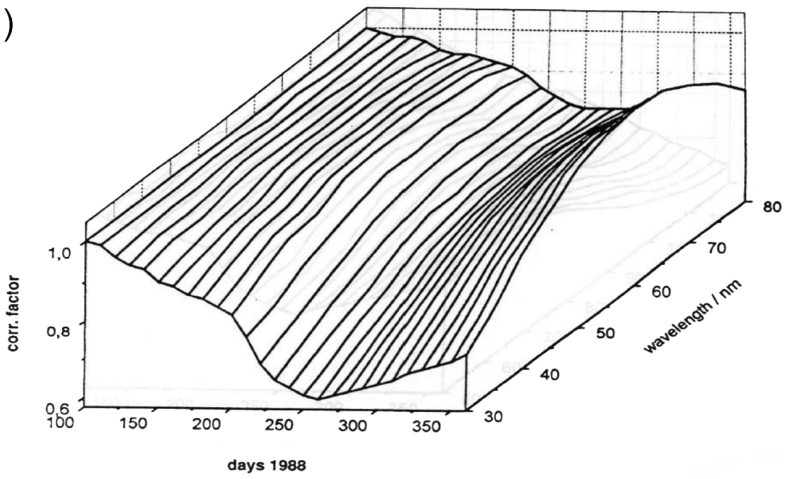

(b)
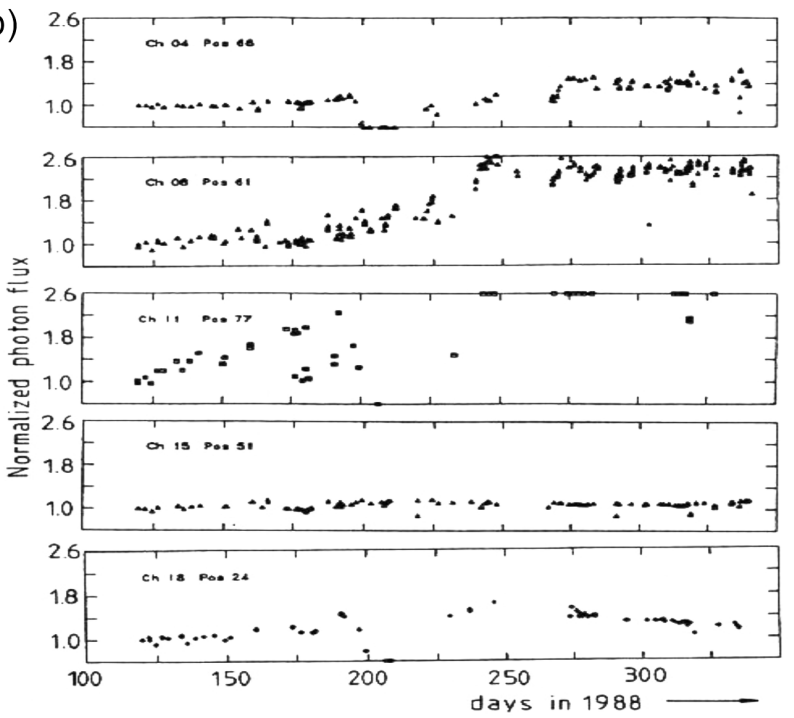

Figure 14. (a) Airglow-solar spectrometer instrument: efficiency changes of 1 channel $(30-80 \mathrm{~nm})$ out of 18 channels covering the spectral range from 20 to $700 \mathrm{~nm}$ (courtesy of J. Worden and T. Woods, 1996). (b) Airglow-solar spectrometer instrument: efficiency changes of five channels recording the solar emission line hydrogen Lyman- $\alpha$ at $121.57 \mathrm{~nm}$.

with the history of the fabrication tools and their previous use included. For example, coating of an optical grating is affected by the purity of the coated material such as platinum and remnants from the evaporating source and the gas composition in the equipment. The coating is amorphous, enclosing gaseous and fractional impurities. This coated compound strongly changes in the laboratory environment, during testing in vacuum, during integration and qualification of the instrument, during calibration, during the transport to the launch site, during launch and opening to the space environment, even stronger when exposed to cosmic radiation and most strongly by exposing it to EUV radiation for measurement. Since the latter ones interact with the optical surfaces at energy levels exceeding $100 \mathrm{eV}$ tremendous individual surface changes occur at each point of the grating and or/other component. Processes like internal diffusion of em- 


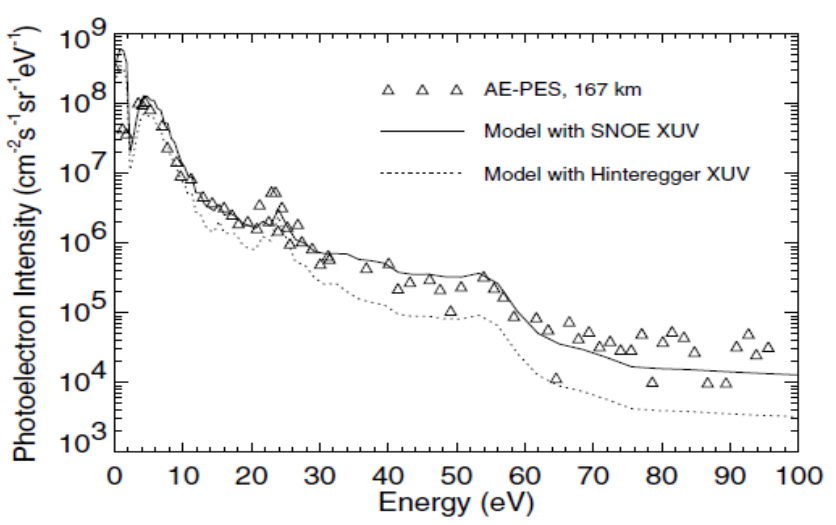

Figure 15. Modeling photoelectron densities based on SNOE data (black line) and on the Hinteregger XUV model deviate by a factor of 4 with respect to the XUV flux input (Solomon et al., 2001; copyright permission granted by Wiley publishing).

bedded gases, fractionation of molecules at the surface (water vapor, hydrocarbons), detachment of atoms, crystallization and/or de-crystallization and, even worse, removal of upper layers, e.g., carbon from AlC filters, are only dominant changes showing that it is impossible to trace efficiency caused by surface changes at one optical component. This is also true, if "protected" components are used for intercomparisons with "active" ones. Both types of components do change with time in a different way. Taking into account that at minimum two optical components are required for operating a EUV spectrometer there is no possibility of tracing efficiency changes accurately except for recalibrating the instrument repeatedly in space. One possibility of achieving this task is proposed by Schmidtke (1976b).

During the 20th century most data are collected in the spectral region of 100-200 nm with a relatively good temporal coverage of the solar fluxes (Fig. 16). Below $100 \mathrm{~nm}$ there are substantial gaps marked as "EUV holes" (Donnelly, 1987) without EUV measurements aboard satellites. In addition to the satellite missions a few EUV spectrometers are flown mostly for the purpose of cross-calibrating satellite instruments.

However, until the end of the 20th century there was no instrument with in-orbit recalibration capability available. Therefore, only rough estimates on the accuracy of EUV data are published for this period.

Though the science community was working thoroughly on the quantitative validation of EUV-SSI data until the end of the last century, the technological limitations in this field of research hampered the presentation of a set of validated EUV-SSI data covering a solar cycle. However, the qualitative results led to a better understanding of the physical processes controlling the terrestrial ionospheric/thermospheric system.

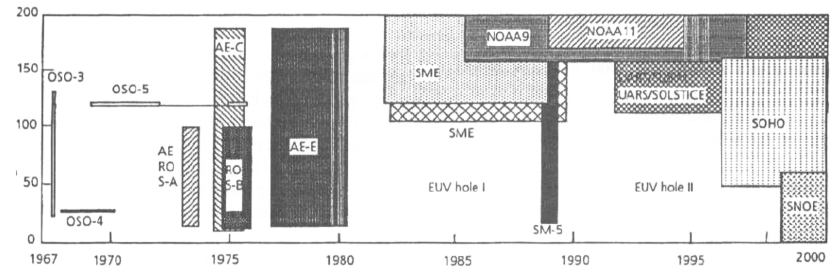

Figure 16. With $x$ axis in time (years) and $y$ axis in wavelength (nm): UV/EUV satellite missions until 2000 (Schmidtke, 2000b): Orbiting Solar Observatory (OSO); Aeronomy Satellite (AEROS); Atmospheric Explorer (AE); Solar Mesospheric Explorer (SME); National Oceanic and Atmospheric Administration (NOAA and UARS/SOLSTICE); San Marco satellite (SM); Upper Atmospheric Research Satellite (SM); Solar and Heliospheric Observatory (SOHO); Students Nitric Oxide Explorer (SNOE); (Schmidtke et al., 2000b; copyright permission granted by Elsevier publishing).

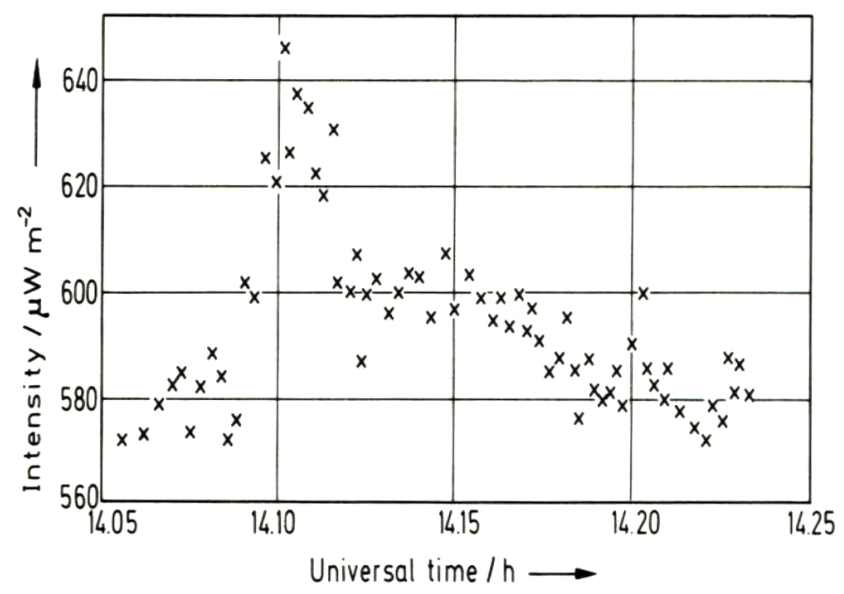

Figure 17. Recording of the He II emission line at $30.4 \mathrm{~nm}$ aboard the satellite AEROS-A during a 2B solar flare on 15 June 1973 shows typical solar short-term variability (Schmidtke, 1978; copyright permission granted by Elsevier publishing).

\section{State of the art of EUV-SSI results at the end of the 20th century}

The first photoelectric recordings aboard the satellites OSO1, OSO-3 and OSO-4 (Hall and Hinteregger, 1970; Timothy and Timothy, 1979) exhibited indications for solar EUV variability exceeding solar VIS changes by orders of magnitude. Evaluating also the data from the missions shown in Fig. 16, there are three types of typical variability: short term, solar rotation, and solar cycle changes.

Short-term changes (Fig. 17) are reported in several publications such as by Kocharov et al. (2000) and by Schmidtke (1984). Variability of the total EUV flux up to about $25 \%$ is observed on a relative intensity scale. The intensity changes with respect to intensity differ with wavelength (Hall and Hinteregger, 1970) as it is shown also for solar rotation peri- 


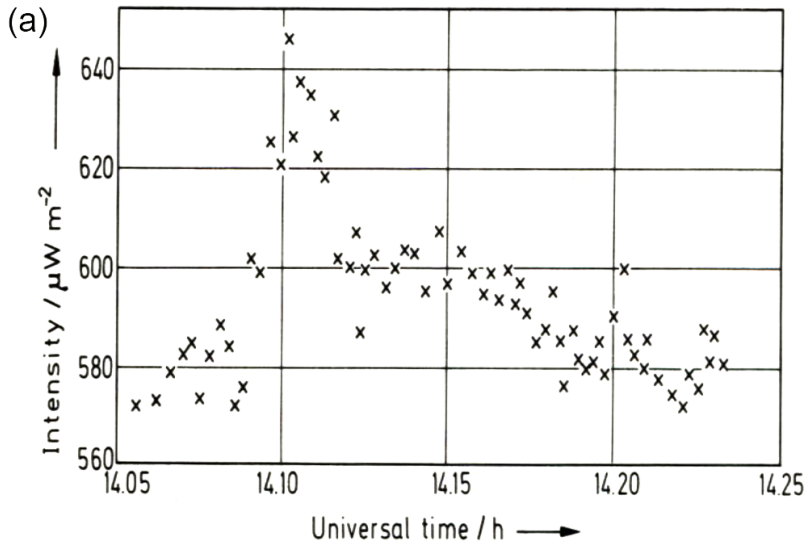

(b)

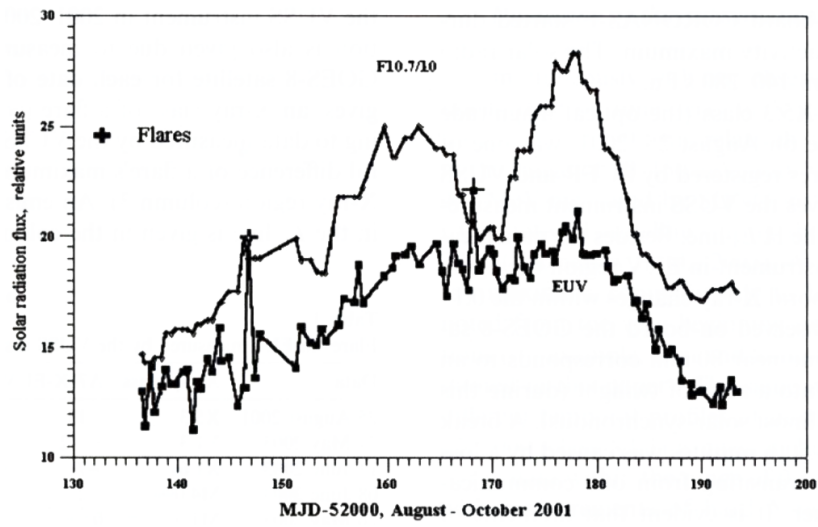

Figure 18. (a) Solar rotation variability of selected emissions (Hall and Hinteregger, 1970; copyright permission granted by Wiley publishing). From top to down: He II at $30.4 \mathrm{~nm}$; C III at $97.7 \mathrm{~nm}$; H I at $102.5 \mathrm{~nm}$; O VI at $103.2 \mathrm{~nm} ; \mathrm{O} \mathrm{V}$ at $63.0 \mathrm{~nm}$; He I at $58.4 \mathrm{~nm} ; \mathrm{Fe}$ XVI at $33.5 \mathrm{~nm}$, and below Covington index $\left(F_{10.7}\right)$. (b) EUV flux and Covington index $\left(F_{10.7}\right)$ variability with solar rotation (Nusinov et al., 2006; copyright permission granted by Elsevier publishing).

ods (Fig. 18a). Similarly, the amplitudes of EUV variability and the F10.7 index do not match with each other (Fig. 18b).

Considering the variability of the total flux with solar rotation, increases of up to $40 \%$ are observed (Fig. 18b).

Given that prior to the year 2000 there was no measurement available covering a full solar cycle of about 11 years (Fig. 16), some relative estimates on the solar variability are published. Measurements aboard the AEROS-A satellite show a decrease of the total EUV flux by about $30 \%$ during the first 200 days of 1973 (Fig. 19) while the smoothed sunspot numbers decreased from 55 to 36 (Schmidtke, 1976a). This was the first set of measurements covering the complete wavelength range from 103 to $16 \mathrm{~nm}$ and a period of 8 months. In-flight calibration of the electron multipliers with a radioactive source of $\mathrm{Ni} 63$ source was applied for the first time. Based on these measurements (Fig. 13a) the data are corrected.

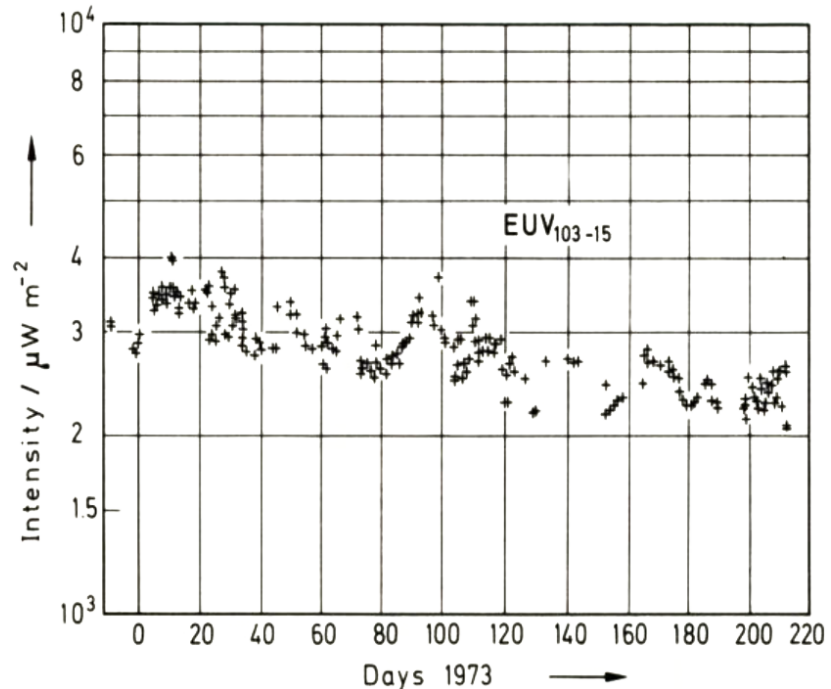

Figure 19. AEROS-A solar EUV flux data between 15 and $103 \mathrm{~nm}$ (Schmidtke, 1976a; copyright permission granted by Wiley publishing).

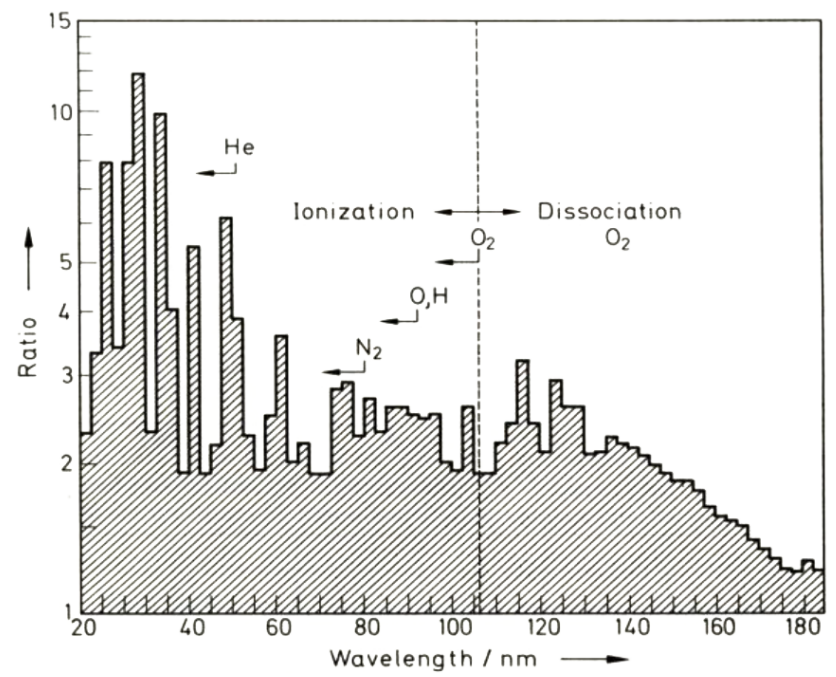

Figure 20. EUVS data from the satellite AE-E (Hinteregger, 1981; copyright permission granted by Elsevier publishing). Ordinates: rate of change from July 1976 (solar activity minimum) to January 1979 (close to maximum).

Results of the EUVS (Extreme Ultraviolet Sensor) experiment aboard the AE-E satellite (Hinteregger, 1981) demonstrate the variability of the EUV-SSI from 20 to $185 \mathrm{~nm}$ during the period from July 1976 (solar minimum) to January 1979 (close to the solar maximum). The magnitude of SSI EUV flux changes range from about $30 \%$ at $185 \mathrm{~nm}$ to more than a factor of 10 at $28 \mathrm{~nm}$ (Fig. 20). Long-term variability was also reported by Kazachevskaya and Katyushina (2000), Ivanov-Kholodny (2000), Mikhailov (2000), and Nusinov (2006). 
Using solar EUV data available, semi-empirical EUV models are developed. For example, with data from the satellite mission ASSI aboard San Marco 5 (Fig. 16) and with data from a calibration rocket of the University of Colorado, Boulder, flown on 10 November 1988, a solar EUV irradiance reference spectrum is derived (Schmidtke et al., 1992). In addition, Tobiska et al. (1993) published the results of a study comparing ASSI and other measured EUV data in the spectral range from 4 to $105 \mathrm{~nm}$ with modeled EUV data. Reference spectra are also published by Thuillier et al. (2004a, b), Warren (2005) and Woods et al. (2009).

The necessity for monitoring EUV-SSI during longer periods was repeatedly requested in COSPAR recommendations but it could not be realized until the end of the last century (Fig. 16). For this reason the Covington index $F_{10.7}$ (flux at the $10.7 \mathrm{~cm}$ radio wavelength) was and still is used as proxy to quantify the solar EUV variability, though the solar radio emission is neither physically interacting with the T/I system nor is it generated by the same physical processes within the same altitude regions of the solar atmosphere. Consequently, the correlation of $F_{10.7}$ with the EUV solar fluxes does not meet the current requirements anymore. For modeling physical processes generated by the absorption of solar EUV photons EUV-SSI data are required. For these and other applications EUV indices for solar-terrestrial relations are proposed (Schmidtke, 1976a).

The problem of assigning reliable numbers to the accuracy of EUV-SSI data was not solved at that time. One method for performing solar XUV measurements with in-flight calibration (Schmidtke, 1976b) was proposed and discussed with Russian delegates to be flown aboard the Mir orbital space station but it could not be realized.

The calibration method is shown schematically in Fig. 21: after the solar radiation passes a monochromator with planar grating geometry (Schmidtke et al., 1974) the nearly monochromatic photon flux is determined quantitatively by an ionization chamber that is a primary detector standard. By removing the calibration detector, the known monochromatic photon flux enters and calibrates the spectrometer. Repeating this procedure for different wavelengths and with time the spectrometer is recalibrated whenever required. By removing the monochromator and the ionization chamber the solar flux enters the calibrated EUV spectrometer.

Summarizing, the state-of-the-art development of new methods providing long-term EUV-SSI data sets of a validated accuracy at a $10 \%$ level became an important issue in the following century.

\section{EUV-SSI data derived after the year 2000}

The results from rocket and satellite missions conducted during the twentieth century paved the way for the breakthrough targeted since long providing validated EUV-SSI data. In the field of EUV spectroscopy the requirements on

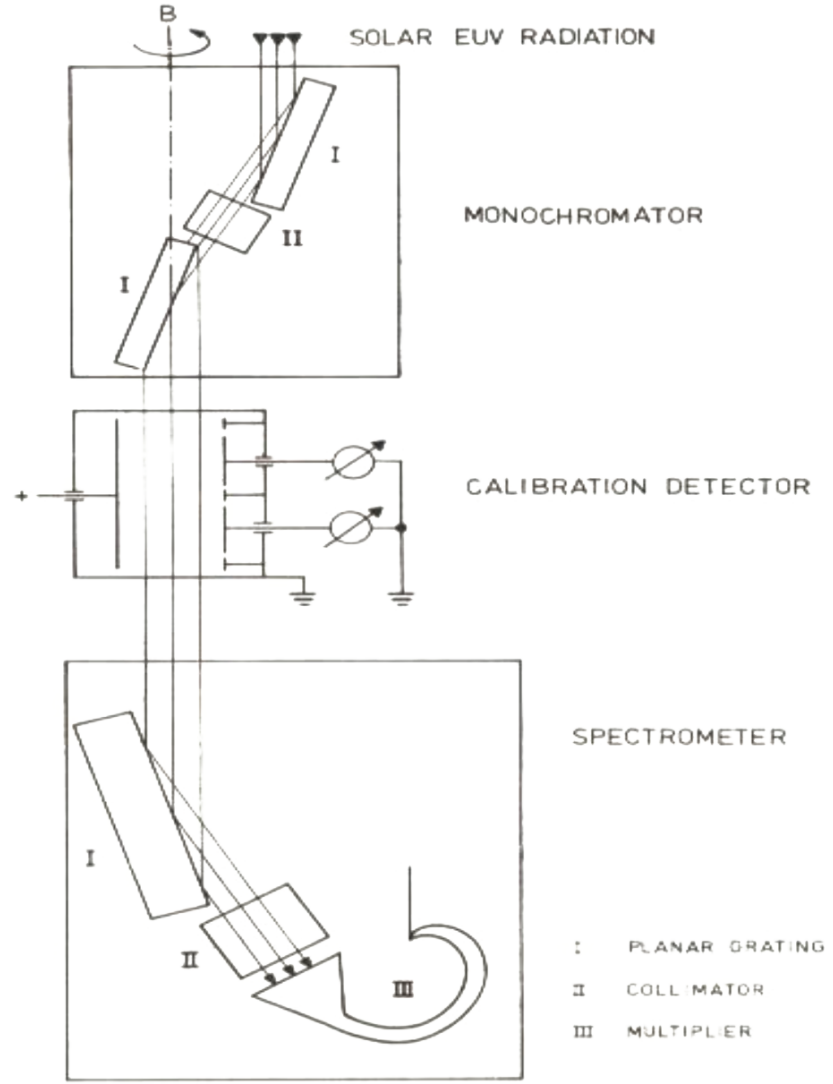

Figure 21. Instrumental arrangement for in-flight calibration of XUV spectrometers (Schmidtke, 1976b; copyright permission granted by De Gruyter Rights \& Licenses Department).

higher standards of SSI accuracy are noted due to a strongly growing interest in this field of research from physical and semi-empirical ionospheric/thermospheric modeling, radar and GNSS data evaluation, and climate modeling activities (Meehl et al., 2009) taking into account the deposition of energy in different altitude regions, e.g., to learn more about the vertical heat transfer up to altitudes of $500 \mathrm{~km}$.

Most of the groups applied electron synchrotron radiation as a calibration standard on ground (Woods and Rottman, 1990; Woods and Eparvier, 2006). Once per year a rocket payload is flown as an under-flight to a satellite cross-calibrating the EUV instrument aboard the spacecraft. Hochedez et al. (2006) used doubled filter sets with one set for regular measurements and the other one protected for minimizing degradation. Intercomparing the transmission of both filters shall help to trace the instrumental efficiency.

Another method implies the incorporation of ionization chambers in the space EUV spectrometer system as described in Fig. 21 (Schmidtke, 1976b). Replacing the monochromator by narrow bandpass filters the in-flight calibration is repeatedly applied on demand as accomplished with the instrument Solar Auto-Calibrating EUV/UV Spectrometers (SolACES) aboard the payload SOLAR at 
the Columbus Module of the International Space Station (Schmidtke et al., 2006a, 2014) as shown in Figs. 22a-d.

To demonstrate the progress made, the following is a short overview of the latest missions.

- SOHO/SEM (Judge et al., 2000): since the beginning of 1996 the Solar Extreme Ultraviolet Monitor (SEM) records the full disk solar EUV and XUV irradiance in the bandpass of $30.4 \pm 4.0 \mathrm{~nm}$ and of $0.1-77 \mathrm{~nm}$, respectively.

- SNOE (Bailey et al., 2006): the SNOE satellite made daily solar observations of the solar soft X-ray irradiance over most of the period from 10 March 1998 to 16 March 2002. Wavelengths below $30 \mathrm{~nm}$, referred to as soft X-rays, were measured in broadband channels.

- TIMED/SEE (Woods et al., 2000, 2005; Woods and Eparvier, 2006; Woods, 2008): since the launch of the Thermosphere, Ionosphere, Mesosphere Energetics and Dynamics (TIMED) satellite in December 2001, the Solar EUV Experiment (SEE) measures the solar SSI EUV in the spectral range from about 27 to $190 \mathrm{~nm}$ with $0.4 \mathrm{~nm}$ spectral resolution and in broadbands between 0.1 and $30 \mathrm{~nm}$.

- SOLAR/SolACES (Schmidtke et al., 2006a, 2014): since the launch of the payload SOLAR on 8 February 2008 with the SolACES, it measures SSI EUV data in the spectral range from 16 to $150 \mathrm{~nm}$. The mission is extended to February 2017.

- CORONAS-PHOTON/PHOKA (Kotov et al., 2011; Pflug et al., 1996): the satellite was launched into orbit on 30 January 2009. The PHOKA instrument intended to measure the absolute flux of solar electromagnetic radiation in the spectral windows of $0.5-7 \mathrm{~nm}$, $0.5-11 \mathrm{~nm}, 27-37 \mathrm{~nm}$, and $116-125 \mathrm{~nm}$. Before the launch, photodiodes of the instrument had been calibrated using a synchrotron radiation source. In-flight stability of the sensitivity of the main channels was controlled using calibration channels.

- GOES-13 and GOES-15 (Evans et al., 2010): EUVSSI measurements with the EUVS include broadband recordings in channels $5-15 \mathrm{~nm}, 25-34 \mathrm{~nm}, 42-63 \mathrm{~nm}$, $17-81 \mathrm{~nm}$, and $118-127 \mathrm{~nm}$ since August 2006. A nextgeneration GOES-R EUVS and XRS (X-ray sensor) of the GOES program with more expanded capabilities than the GOES EUVS is being prepared to start in 2016 (Eparvier et al., 2009; Chamberlin et al., 2009).

- PROBA-2/LYRA (Hochedez et al., 2006): the Lyman- $\alpha$ radiometer was launched on board the Proba-2 satellite in November 2009. In four channels, new technology components are to be tested covering the wavelength intervals of $115-125 \mathrm{~nm}, 200-220 \mathrm{~nm}, 17-50 \mathrm{~nm}$ and $1-$ $20 \mathrm{~nm}$.

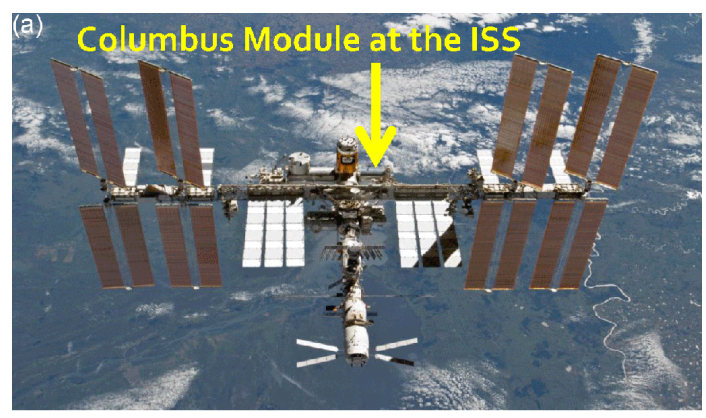

(b)

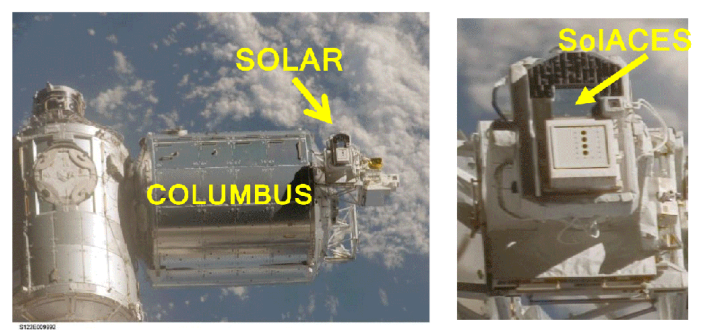

(c)

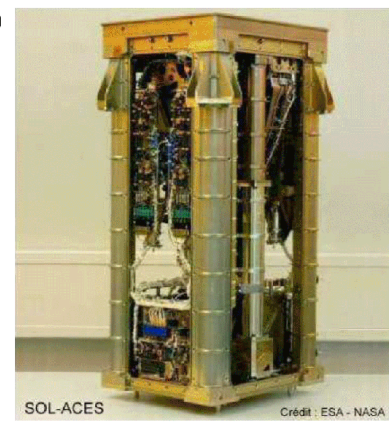

(d)

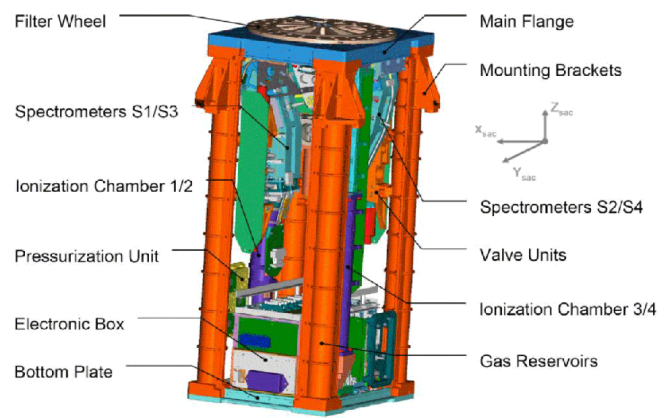

Figure 22. (a) Position of the Columbus Module at the International Space Station (credit: ESA-NASA). (b) Position of payload SOLAR with SolACES at the Columbus Module of the ISS (credit: ESA-NASA). (c) SolACES aboard the ISS (credit: ESA-NASA). (d) SolACES includes four spectrometers and two three-current ionization chambers. The filter wheel with 48 apertures selects narrow intervals of the solar EUV spectrum for ionization chamber measurements. The gas reservoirs are structural elements of the instrument simultaneously (Schmidtke et al., 2006a; copyright permission granted by Elsevier publishing). 
- SDO/EVE (Woods et al., 2010): since May 2010 the EUV Variability Experiment aboard the Solar Dynamics Observatory measures the solar SSI EUV in the 0.1$105 \mathrm{~nm}$ range with $0.1 \mathrm{~nm}$ spectral resolution and with 20 s cadence.

With this pool of instrumentation two aspects of data accumulation are realized. It is the continuous monitoring and the data evaluation at higher accuracy standards. Work is ongoing for elaborating a validated EUV data set covering a period of a full solar cycle for the first time.

Progress made is demonstrated in Fig. 23a-c (Unglaub et al., 2011, 2012) applying EUV data for modeling EUV energy deposited in the thermosphere from 2002 to 2010 (Fig. 23c). The results confirm a better correlation using measured EUV data rather than the index $F_{10.7}$ (Fig. 23a). The latter is also true for its comparison with the measured global total electron content (Fig. 23b). The differences appear most strongly during solar minimum conditions (about days 21902920 in years 2008 and 2009). In this intercomparison no particle contribution from solar energy input to the T/I system is taken into account.

\section{EUV airglow and auroral measurements}

There are two solar energy sources generating EUV airglow and EUV auroral emissions in the upper atmosphere. These sources are the solar EUV radiation and the solar particle emission named solar wind with coronal mass ejections (CMEs) included.

Airglow is produced primarily by the solar EUV radiation. For this reason the Airglow-Solar Spectrometer Instrument aboard the Italian-American aeronomy satellite San Marco 5 is designed to measure equatorial airglow emissions in addition to the solar radiation in the spectral domain from 20 to $700 \mathrm{~nm}$. In 18 channels with dynamic ranges of up to $1-10^{13}$ in the visible spectrum, the instrumental field of view moved from the zenith to the nadir direction (Schmidtke et al., 1991, 1993) while the satellite rotated at a spin rate of $6 \mathrm{rpm}$. In this way the reaction of the thermosphere/ionospheric (T/I) system on strongly varying solar EUV fluxes is recorded for different T/I spacial, local time, and solar activity conditions.

Airglow emissions showed strong differences for optically thin and thick lines depending on descending altitudes during the lifetime of the spacecraft as well as on sensingpronounced source regions. During the mission, the spacecraft altitude range of observation changed from 619 to about $200 \mathrm{~km}$ sensing airglow in situ of its center of origin. Figures $24 a-c$ show the solar input spectrum and typical airglow features recorded during one spin rotation including emissions from molecular nitrogen and from neutral and ionized oxygen.

Since each of the airglow emission lines is transporting information on the temporal state of the thermospheric/ionospheric system, airglow measurements are pow- (a)

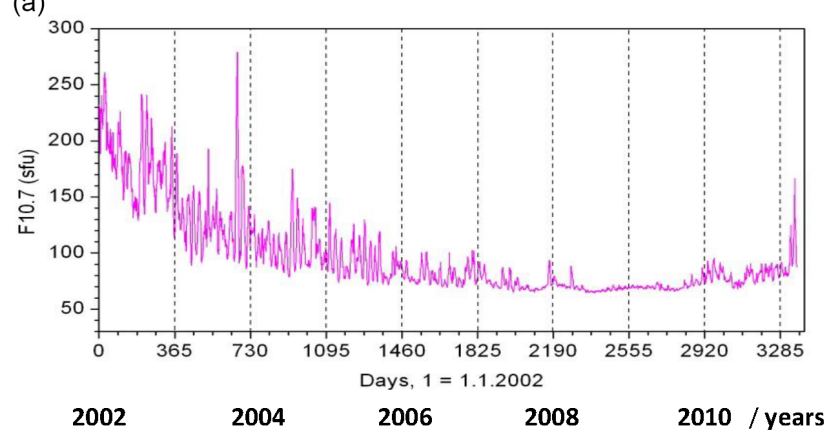

(b)

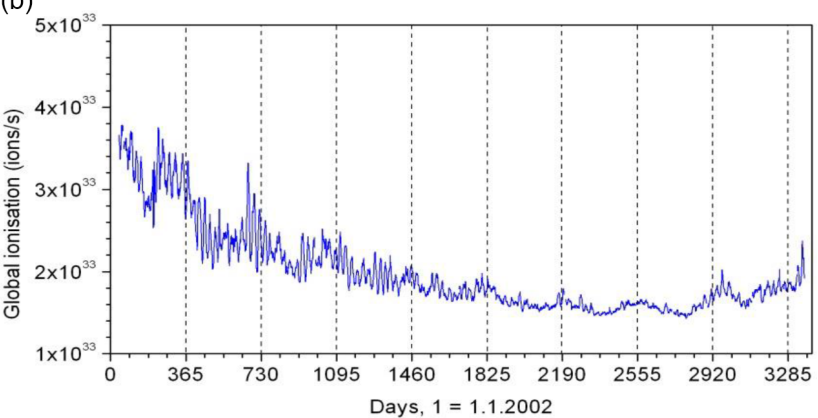

(c)

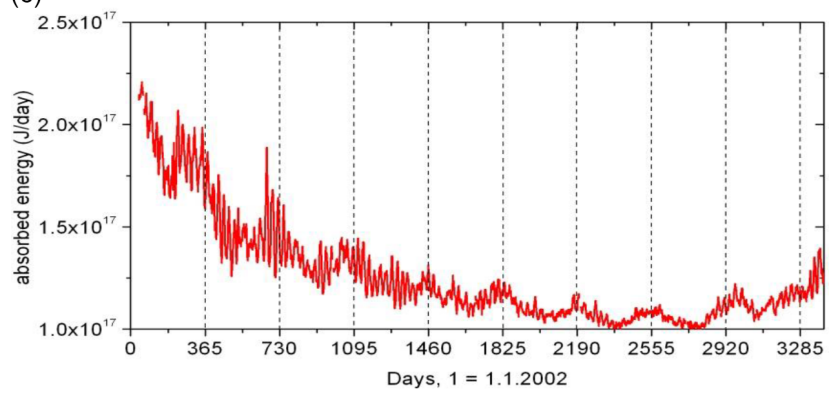

Figure 23. (a) Presentation of the $F_{10.7}$ index from 2002 to 2010 (Unglaub et al., 2012; copyright permission granted by University of Leipzig). (b) Measured global total electron content from 2002-2010 (Unglaub et al., 2012; copyright permission granted by University of Leipzig). (c) EUV energy deposited in the thermosphere from 2002-2010 (Unglaub et al., 2012; copyright permission granted by University of Leipzig).

erful tools to observe the interaction of the solar EUV radiation with the upper atmosphere and with the particles originated from the solar wind with space weather events generated by coronal mass ejections included. Using the information inherent in the optically thin and optically thick emissions, physical processes can be allocated to active altitude regions when viewing all angles between zenith and nadir as performed by the spinning low-earth orbiting satellite San Marco 5. Most of the airglow emissions are excited by impact with photoelectrons which are produced by absorbing EUV photons in the thermosphere. Resonant scattering, recombination processes and fluorescent scattering play a minor role with airglow, each. Accordingly, given the lower energy dis- 


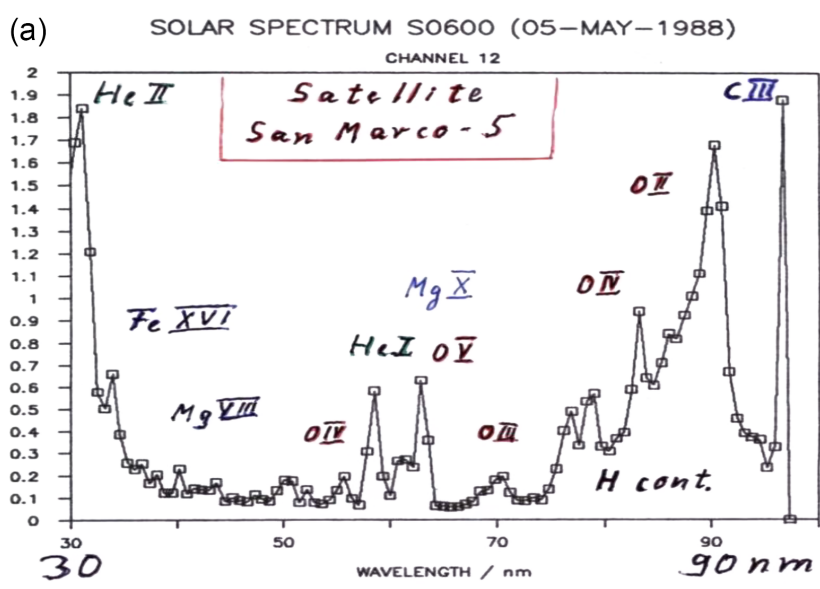

(b)

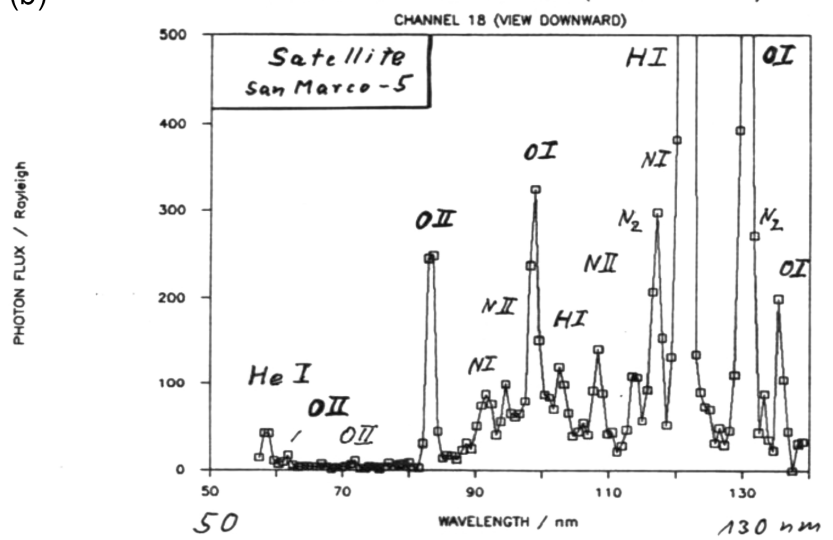

(c)

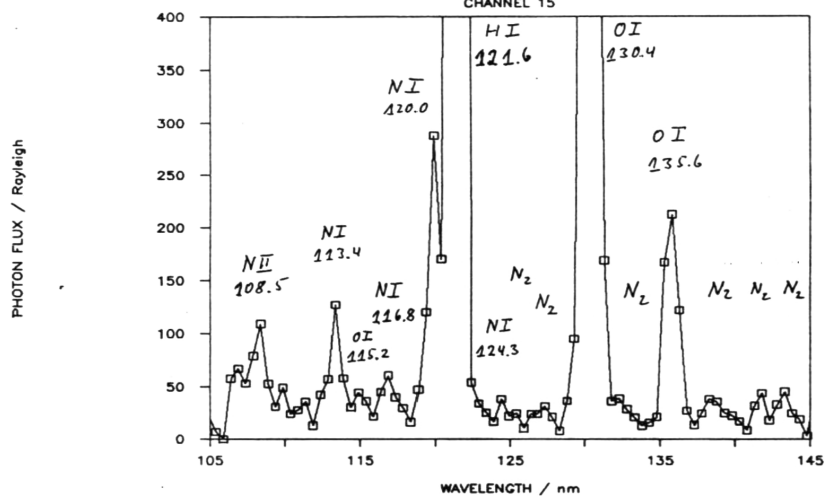

Figure 24. (a) Solar EUV fluxes in $10^{10}$ photons $\mathrm{m}^{-2} \mathrm{~s}^{-1}$ (Schmidtke et al., 1991; copyright permission granted by Elsevier publishing). (b) Terrestrial airglow EUV fluxes (Rayleigh units) in the equatorial region recorded in Channel 18 (Schmidtke et al., 1991; copyright permission granted by Elsevier publishing). (c) Terrestrial airglow EUV fluxes (Rayleigh units) in the equatorial region recorded in Channel 15 (Schmidtke et al., 1991; copyright permission granted by Elsevier publishing).

tribution of the photoelectrons far below $100 \mathrm{eV}$ the excited airglow emissions of the T/I system are primarily generated by neutral atoms and molecules. The resonance emissions

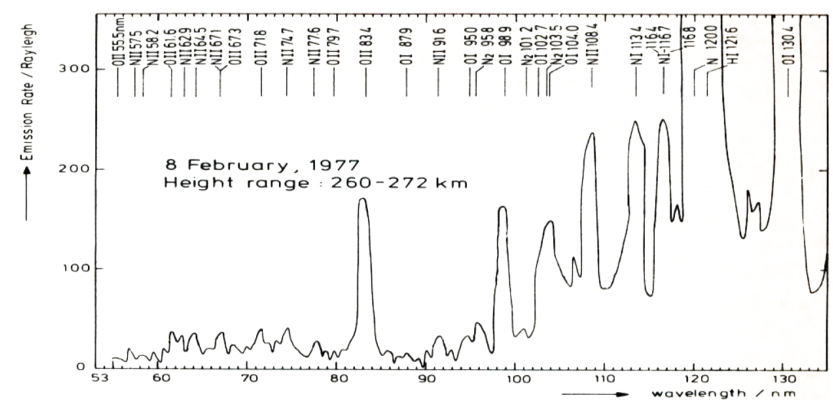

Figure 25. Emission spectrum of a diffuse aurora on 22 January 1977 over Andøya, Norway (Fischer and Schmidtke, 1980; copyright permission granted by Wiley publishing).

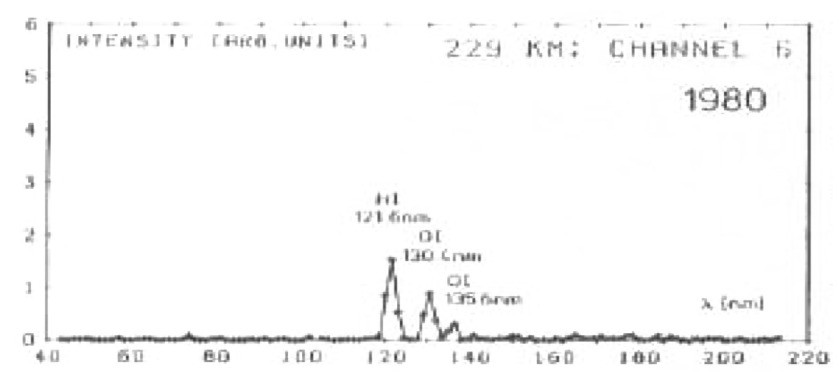

Figure 26. Emission spectrum of an oscillating diffuse aurora on 16 November 1980 over Kiruna, Sweden (Schmidtke et al., 1983; copyright permission granted by Elsevier publishing).

of $\mathrm{H}^{+}, \mathrm{O}^{+}$and $\mathrm{He}^{+}$contribute to the airglow spectra, too. These and other emissions from ions provide information on the physical processes of the ionosphere.

As airglow is primarily excited by low energetic photoelectrons, auroral emissions show features requiring higher electron energies. Exploring the mythical glow at high atmospheric altitudes three different auroral types are investigated launching four rockets with spectrometers and photometers covering the EUV through the visible spectral ranges. During the rocket campaign Polar High Atmosphere, rockets were launched on 22 January and on 8 February 1977 transporting EUV spectrometers, electron spectrometers, and other instruments and sensing parameters to investigate diffuse electron aurorae (Fischer and Schmidtke, 1980; Fischer et al., 1980; Theile et al., 1981). Height profiles of spectral emissions such as O I $(130.4 \mathrm{~nm}), \mathrm{H} \mathrm{I}(121.6 \mathrm{~nm})$, N I $(120 \mathrm{~nm})$, O I $(98.9 \mathrm{~nm})$, O II $(83.4 \mathrm{~nm})$, and emission spectra from 50 to $150 \mathrm{~nm}$ are recorded up to $270 \mathrm{~km}$, as were the emissions in the spectral domain of $50-80 \mathrm{~nm}$ are of special interest.

Two more EUV spectrometers were flown at the Energy Balance Campaign on 16 November 1980 and on 9 December 1981 over Kiruna, Sweden, during an oscillating diffuse aurora and a stable arc, respectively. The spectral wavelength range extended from 50 to $650 \mathrm{~nm}$. The spectrometers and photometers recorded spectra and selected height profiles of the emissions of $\mathrm{O}$ I at 130.4 and $557.7 \mathrm{~nm}$, of $\mathrm{N}_{2}$ at 
(a)

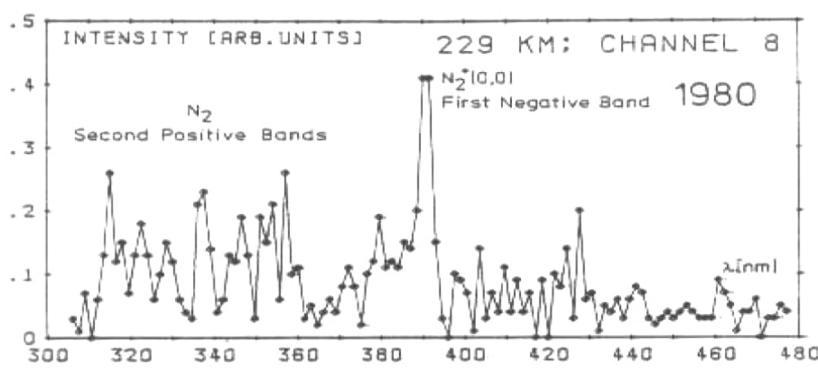

(b)

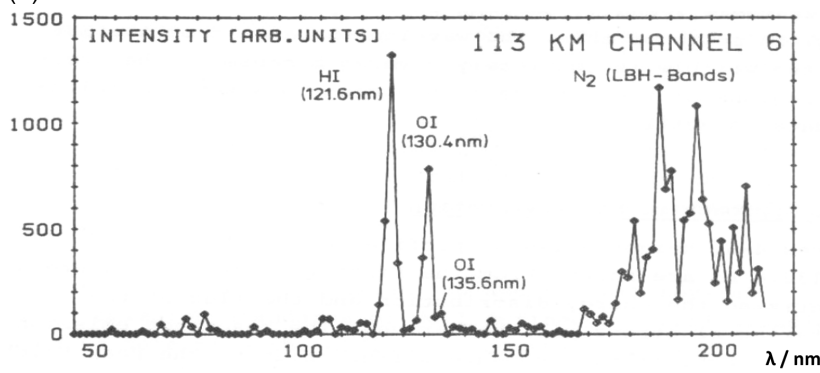

Figure 27. (a) Emission spectrum of an oscillating diffuse aurora between 300 and $480 \mathrm{~nm}$ on 16 November 1980 over Kiruna, Sweden. Intensity is in arbitrary units (Schmidtke et al., 1983; copyright permission granted by Elsevier publishing). (b) Emission spectrum of an oscillating diffuse aurora between 50 and $200 \mathrm{~nm}$ on 16 November 1980 over Kiruna, Sweden. Intensity is in arbitrary units (Schmidtke et al., 1983; copyright permission granted by Elsevier publishing).

$337.1 \mathrm{~nm}$, of the $\mathrm{N}_{2}^{+}$at $391.4 \mathrm{~nm}$, and others (Schmidtke et al., 1983). The payloads contained also an IR spectrometer, an electrical field instrument, a low energy particle spectrometer, a thermal plasma experiment, and a mass spectrometer. Auroral emissions are interpreted taking into account data derived from other experiments and ground-based observations (Schmidtke et al., 1985; Tobiska et al., 1993).

Figure 28 shows an altitude-dependent time delay of geospheric disturbances on their way from the polar regions toward the Equator. This type of local variability in the T/I system is observed at geographic latitudes between -38.9 and $-39.7^{\circ}$ of geophysical latitude. It is derived from EUV occultation measurements aboard the satellite AEROS-A (Schmidtke, 1975). The disturbances propagate faster from the polar region toward the Equator at larger altitudes and with relatively higher amplitudes.

EUV airglow and auroral measurements provide the opportunity of investigating the upper atmosphere also in more detail with respect to spatial resolution. Of special interest are quantitative real-time measurements of selected emissions with an airglow camera from orbits of altitudes between 20000 and $36000 \mathrm{~km}$ to quantify and to localize ionospheric turbulence and space weather disturbances for improving GNSS data evaluation for navigation applications with the highest possible accuracy. Noting that there is a more rapid

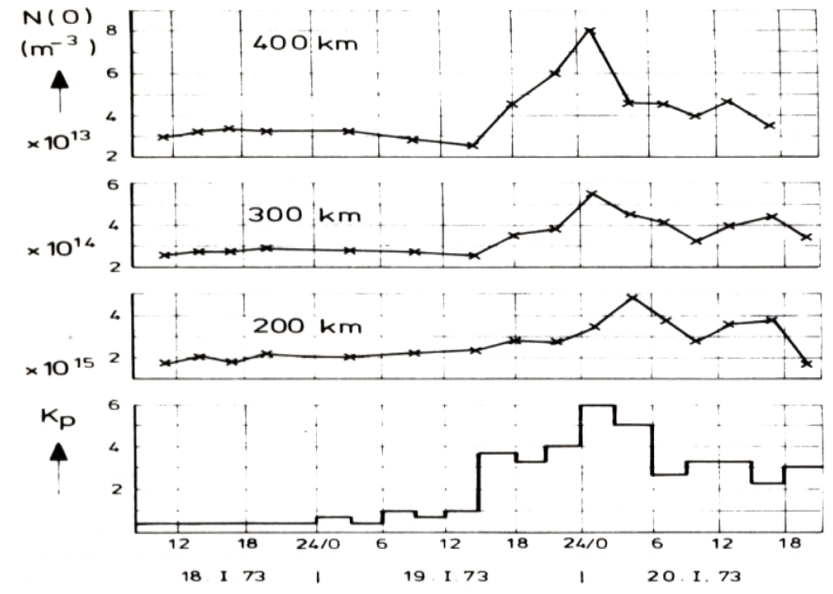

Figure 28. Propagation of geospheric disturbances from polar regions toward the equator with time. Density changes of thermospheric atomic oxygen are derived from EUV occultation measurements (Schmidtke, 1975; copyright permission granted by Wiley publishing).

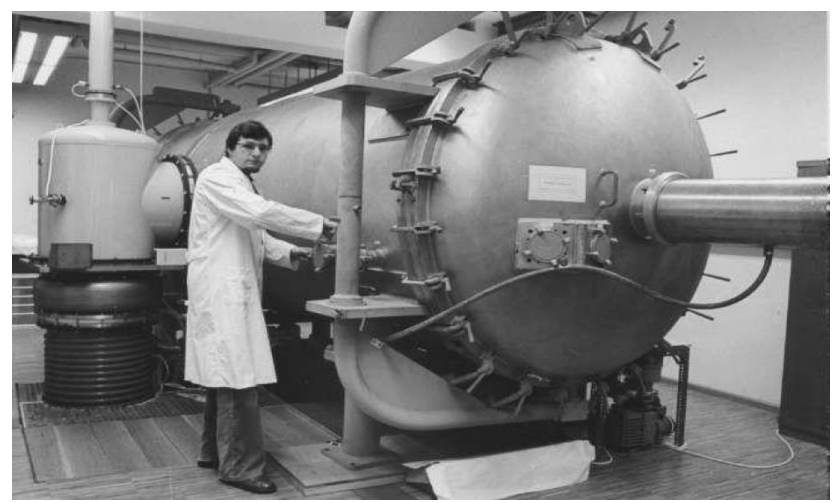

Figure 29. Laboratory equipment for simulating auroral and airglow processes (Strauss, 1980).

propagation of geospheric disturbances in oxygen densities, e.g., at $400 \mathrm{~km}$, some sort of forecasting of stronger space weather events seems to be possible when those disturbances arrive later at lower altitudes transporting more energy within higher atmospheric particle densities, e.g., at $200 \mathrm{~km}$.

\section{Laboratory support for EUV spectroscopy in space}

Development of space instrumentation requires versatile equipment in the laboratory such as special engineering and scientific capabilities, devices for simulating space parameters in a space-like environment, test and qualification equipment. Some examples are outlined in this section.

In order to support space activities in airglow and auroral spectrophotometry, an extraordinary laboratory vacuum chamber of $5 \mathrm{~m}$ length and $2 \mathrm{~m}$ diameter was equipped with 


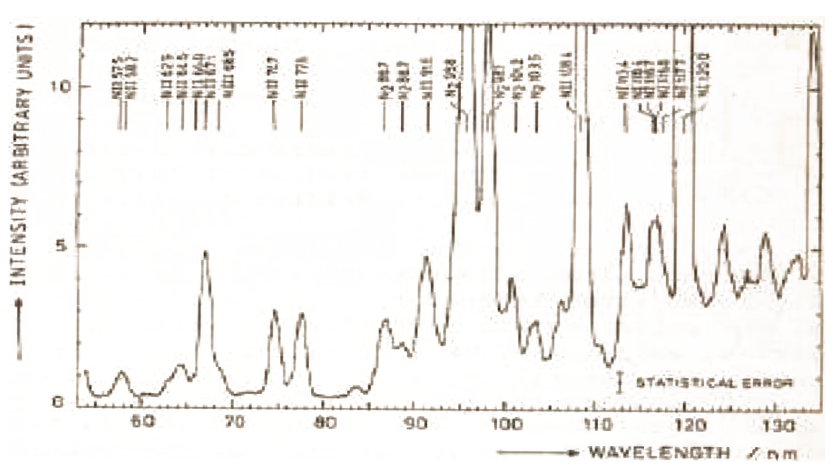

Figure 30. Spectral recording for simulating auroral processes of molecular nitrogen (Fischer et al., 1980; copyright permission granted by Wiley publishing).

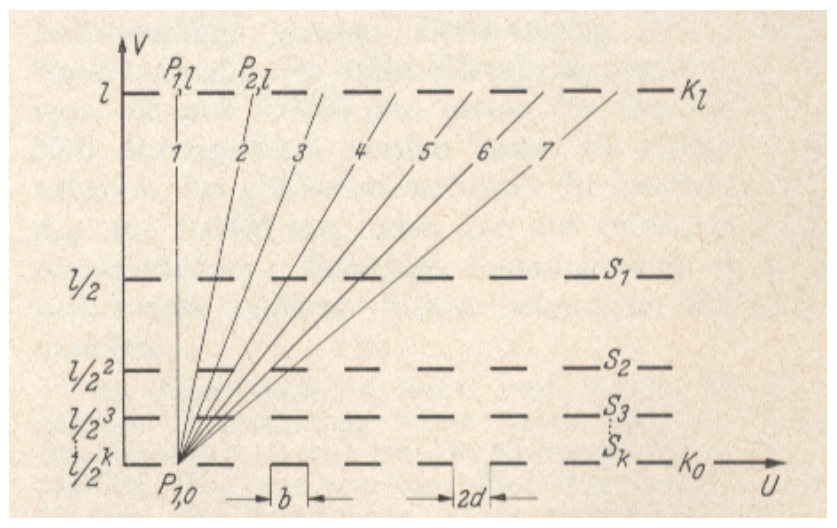

Figure 31. Geometrical arrangement of grids to block perturbing cross rays (Schmidtke, 1968; copyright permission granted by Springer).

electron sources of energies of up to $50 \mathrm{keV}$ for stimulating auroral (Fig. 30) and airglow emissions as well as with diagnostic tools including high-resolution EUV/UV spectrometers.

After the chamber started operation, the space activities of the Fraunhofer Institute for Physical Space Research in Freiburg, Germany, were stopped. In the renamed institute (Fraunhofer Institute for Physical Measuring Techniques) the work concentrated on applied research to support industry.

A mechanical collimator with sun-like divergence of $0.53^{\circ}$ is used for testing space spectrometers based on planar grating geometry. It is based on a Soller collimator system of the grid type with a large number of slits (Fig. 31). The number of grids, the slit width and the distances from one grid to the next grid is following special geometrical conditions (Schmidtke, 1968). This type of collimator is also designed as a diffraction filter (Schmidtke, 1970). Making use of the effect of "ray bundling" it is well suited for X-ray spectrographs and spectrometers (Bruner et al., 1979).

In the laboratory different light sources are designed simulating solar radiation, airglow, and auroral emissions.

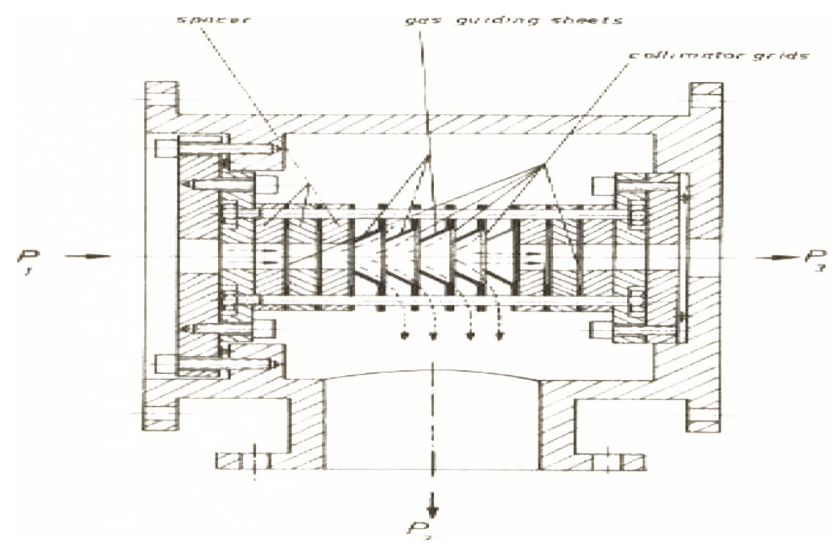

Figure 32. Soller collimator with differential pumping (reproduced from Schmidtke, 1971; copyright 2015, AIP Publishing LLC) designed for transmitting EUV radiation from open EUV sources at 5 mbar to spectrometers at $10^{-5}$ mbar.

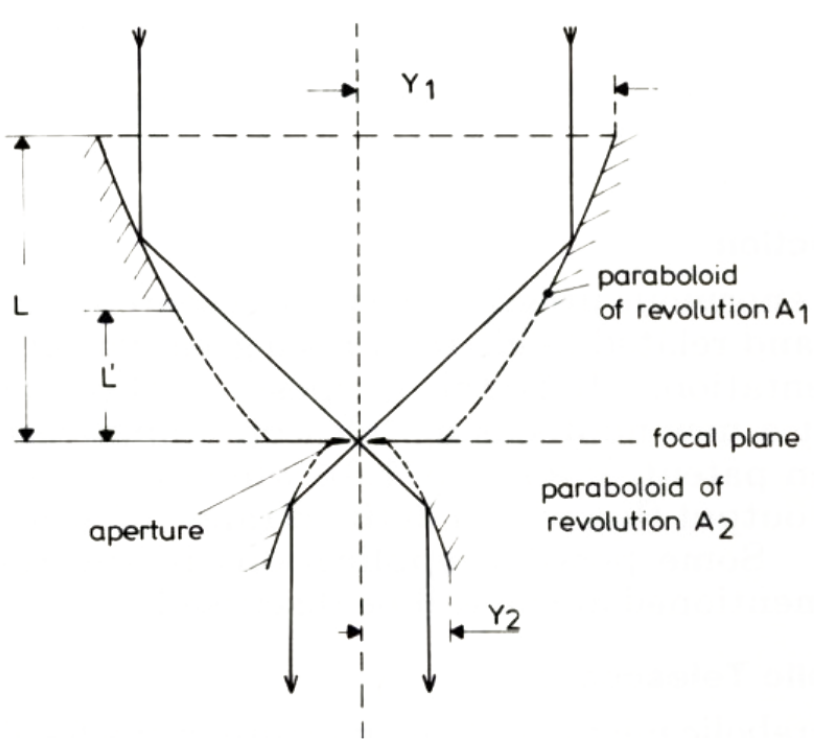

Figure 33. Telescope with two paraboloids of revolution to be used as a collimator (Reprinted from Schmidtke 1977; OSA copyright permission).

Gaseous discharges such as hollow cathode lamps operate at some millibars of pressure while spectrometers require a high vacuum environment. Since spectrometers with planar grating need a broad EUV beam, a great number of slits in a Soller collimator is applied in a way that differential pumping is achieved at the same time.

Another type of collimator is based on a parabolic telescope to be applied in the XUV spectral region (Schmidtke, 1977; Schmidtke et al., 1980). It can be used as a collimator (Fig. 33) with the possibility to change the angular divergence of the incoming photon flux either increasingly or decreasingly. In the latter case, very high spectral resolution 
can be achieved in combination with an echelle-type spectrometer.

Determination of diffraction properties of hydrogen phthalate crystals (Seidl et al., 1977), development of a device for high spectral resolution of the He $58.4 \mathrm{~nm}$ emission as achieved with a resonance absorption spectrometer (Crifo et al., 1980), and the measurement of forward photoemission from carbon foils (Hsieh et al., 1979) are other topics of laboratory work.

Computing the absorption of solar EUV photons, e.g., for ionospheric and/or thermospheric modeling, the absorption cross sections are to be used. While the solar photon fluxes are moving from the top of the thermosphere down to the region of absorption, effective absorption cross sections are changing with altitude in the wavelength range longer than $60 \mathrm{~nm}$. This effect is called "radiation hardening", which is not yet known quantitatively. It is still an unsolved issue (Schmidtke, 2000a).

\section{The TIGER/COSPAR program}

After consideration of the state-of-the-art development of technology with respect to the limited availability of useful EUV-SSI data at the end of the last century, a EUV/UV scientific community came to the conclusion that too many questions were still open. Having this in mind the first TIGER (Thermospheric-Ionospheric Geospheric Research) Symposium was held on 18 and 19 June 1998 in Freiburg, Germany. After presentation and discussion of 28 invited and contributed talks, the attendees of the symposium agreed to establish a long-term TIGER program. The decision is based on the general agreement that, for T/I research as well as for commercial applications in space, the improvement of T/I models replacing proxies by EUV/UV SSI data is absolutely necessary to meet scientific goals. There are a number of scientific questions underlying the goal of understanding solar EUV variability (Schmidtke et al., 2002). In this context, the primary topics formulated at the 5th TIGER/COSPAR Symposium (Schmidtke et al., 2006b) were

- measurement of solar EUV/UV radiation

- EUV/UV space instrumentation and its calibration

- modeling of solar EUV/UV radiation

- modeling of the thermosphere/ionosphere applying EUV data.

Taking into account developments in space weather research and in GNSS, the topics

- measurement of airglow/auroral EUV/UV radiation

- airglow/auroral EUV/UV space instrumentation and its calibration are to be added. The latter topic includes the development of an airglow camera to support the investigation real-time space weather effects. This space weather camera (SpaWeCam) can also be used for measuring and allocating turbulence in the ionosphere deriving more detailed correction procedures for the evaluation of GNSS signals.

Meanwhile, the 10th TIGER/COSPAR Symposium was held at COSPAR in Moscow (2014).

\section{Conclusions and future needs}

EUV spectroscopy in space opened a new and wide field in research and application for solar-terrestrial relations. The continuous changes of the driving parameters in the thermosphere/ionosphere system as controlled by solar activity are now well understood qualitatively. Also, quantitatively good progress is made producing EUV-SSI data with radiometric accuracy on the order of $10 \%$. However, the technological problems caused by aging and/or degradation are still severe, consuming a tremendous part of the work involved and too often leading to revisions of EUV-SSI data versions released. Hence, today's primary requirement is achieving the highest possible radiometric accuracy with minimum efforts on determining efficiency changes in order to increase the working time for science. Following the credo of the author applying ionization chambers as performed with SolACES (Schmidtke et al., 2014), the radiometric accuracy can be improved to $3-5 \%$ depending on wavelength. In this way cross-calibration can be realized between SolACES-like instruments and others used for solar-terrestrial and/or solar research.

Other requirements on EUV-SSI data for solar-terrestrial research and applications are medium spectral resolution and lower cadences to be applied in solar physics research.

- Spectral resolution: below $60 \mathrm{~nm}$, EUV photons are absorbed by ionization continua of the thermospheric constituents implying a spectral resolution of up to about $5 \mathrm{~nm}$. For wavelengths larger than $60 \mathrm{~nm}$, rotationvibration absorption bands require allocation of major solar emissions to the absorbing species. A spectral resolution of $1-2 \mathrm{~nm}$ is sufficient.

- Cadence of EUV measurements: since global spreading of absorbed solar EUV energy is taking up to 2 days, daily values averaged over three to six measurements per day would be adequate for T/I modeling. Special applications like allocation of effects during certain periods could require the knowledge of the activity for this period. If there are solar flares occurring just during the given time frame, temporal resolutions of up to several minutes are of interest for those rare cases.

A combination of the existing instrumentation could meet today's and future needs. 


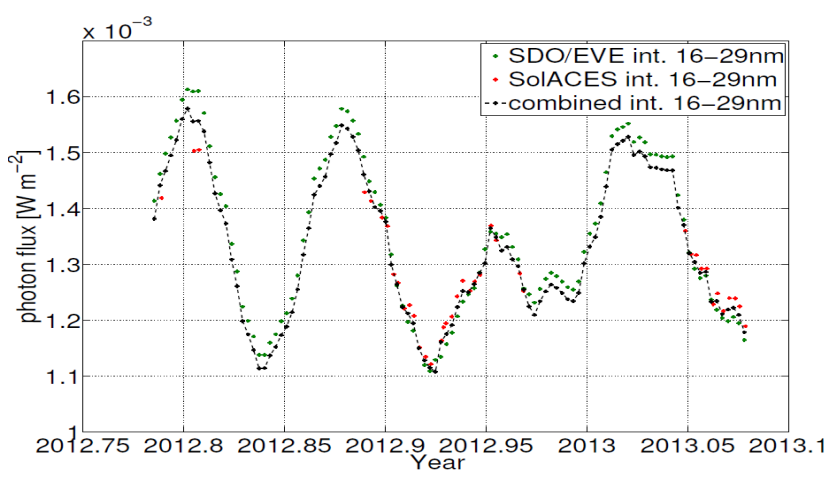

Figure 34. Combined EUV data set from the SDO/EVE and SOLAR/SolACES instruments covering four solar rotations (courtesy of B. Nikutowski and Ch. Erhardt).

Because there is no substitute but measuring the EUV radiation directly and due to the costs involved in realizing the future needs, a strong effort must be started making use of a broad range of worldwide existing resources with respect to manpower, experience, hardware, methods, flight opportunities, and funding resources. The TIGER program with the TIGER/COSPAR symposia as a science platform aims to facilitate the coordination of these existing and future activities focusing on the following aspects, among others:

- EUV/UV-SSI data are now recorded continuously for more than the period of one solar cycle. Composing these data into one set of data to be recommended as a validated data set shall become available for the scientific and application communities. A first approach is presented in Fig. 34 with data from the SDO/EVE and SOLAR/SolACES instruments covering three solar rotations.

- Instrumentation with in-flight calibration capability should be assigned for each wavelength range as the base for cross-calibrating other instruments. In this way a common level for the validation of data from different sources can be assigned.

- Satellite missions with low-cost broadband instruments (one example is presented in Fig. 35) providing continuous real-time measurements of the EUV/UV SSI should be realized.

- Geophysical monitoring of selected airglow and auroral emissions should be established to encompass T/I changes supporting space weather research and further increasing the accuracy of GNSS data.

In this context, the usage and further development of three types of instrumentation are to be considered fulfilling future needs, providing more accurate EUV-SSI data in real time and recording online features of T/I disturbances.

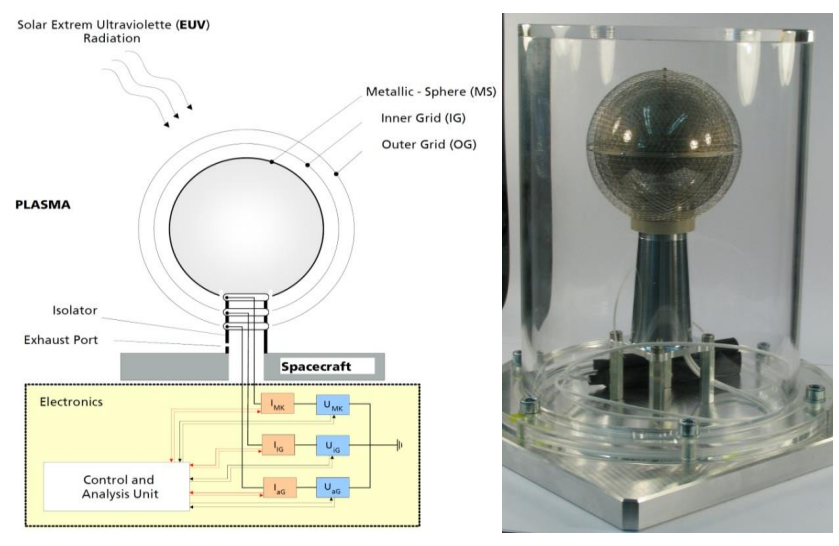

Figure 35. The SEPS sensor consists of three isolated spheres/electrodes connected to sensitive floating electrometers and voltage sources, each. By setting different potentials to the electrodes, measurements of the ambient plasma parameters and of the extreme ultraviolet (EUV) radiation are performed. In this way several measurement modes, such as the following, are possible: Langmuir, plasma shielded Langmuir, RPA (random-phase approximation) electron, RPA ion, EUV radiation and EUV Occultation modes. The metallic surfaces involved are minimizing degradation in the EUV spectral region.

The first type is a low-cost medium-resolution EUV instrument to be applied in real time, e.g., in T/I modeling. The Spherical EUV and Plasma Spectrometer (SEPS) would be a good candidate meeting the requirements for long-term monitoring with stable radiometric efficiency (Fig. 35).

Second, sophisticated EUV spectrometers with in-orbit recalibration capability such as SolACES are required for cross-calibrating other instruments to assure SSI data at high radiometric accuracy.

Third, for tracing geomagnetic, daily and seasonally occurring turbulence in the T/I system, a wide-angle airglow camera is to be developed producing pictures similar to the television weather surveys and weather forecasts. If disturbances are localized, quantified, and allocated aboard GNSS satellites, an on-board procedure can be installed for correcting local propagation delays of navigation signals from space to Earth. Space weather phenomena can be recorded for further investigation, too. (A concept of a spectral terrestrial irradiance camera (STI-Cam) shows the following parameters: a set of telescopes providing an area similar to a primary mirror of $40 \mathrm{~cm}$ diameter, with a field of view $(\mathrm{FOV}) \sim 22^{\circ}$, with $200 \times 200$ pixel resolution, and to be flown at GNSS altitude of $22000 \mathrm{~km}$ would generate up to $100000 \mathrm{cps}$ at $83.4 \mathrm{~nm}$ of O II emitting 800 Rayleigh. Flying over disturbed regions, 3$\mathrm{D}$ pictures will be available. Based on the experience and on the availability of optical components, the development of a spectral terrestrial irradiance camera could be started immediately.)

Science depends on the accuracy of measurements. It is the aim in the field of EUV spectroscopy in space to optimize 
the ongoing efforts for achieving the highest possible accuracy with the resources available while minimizing the work on determining the degradation/aging of the instruments in operation.

Acknowledgements. The author greatly appreciates the stimulation provided by the referees Anatoly Nusinov and Tom N. Woods for improving the content of this publication. Great thanks are also given to Bernd Nikutowski and Christian Erhardt for their support and discussions of the SolACES data.

Edited by: K. Aplin

\section{References}

Bailey, S. M., Woods, T. N., Eparvier, F. G., and Solomon, S. C.: Observations of the Solar Soft X-ray Irradiance by the Student Nitric Oxide Explorer, Adv. Space Res. 37, 209-220, doi:10.1016/j.asr.2005.07.039, 2006.

Baum, W. A., Johnson, F. S., Oberly, J. J., Rockwood, C. C., Strain, C. V., and Tousey, R.: Solar ultraviolet spectrum to 88 kilometers, Phys. Rev. 70, 781-782, doi:10.1103/PhysRev.70.781, 1946.

Bruner, E. C., Acton, L. W., Brown, W. A., Salat, S. W., Franks, A., Schmidtke, G., Schweizer, W., and Speer, R. J.: X-ray spectrometer spectrograph telescope system, SPIE 184, 270-277, Bibcode: 1979SPIE...184..270B, 1979.

Chamberlin, P. C., Woods, T. N., Eparvier, F. G., and Jones, A. R.: Next Generation X-Ray Sensor (XRS) for GOES-R Satellite Series, SPIE Proc., 7438-23, Bibcode: 2009SPIE.7438E..02C, 2009.

Crifo, J. F., Seidl, P. Delaboudiniere, J. P., and Schmidtke G.: Compact resonance absorption spectrometer to monitor the profile of the solar He 58.4 nanometer line, Rev. Sci. Instrum. 51, 321-327, doi:10.1063/1.1136210, 1980 .

Delaboudinière, J. P., Donnelly, R. F., Hinteregger, H. E., Schmidtke, G., and Simon, P. C.: Intercomparison/compilation of relevant solar flux data related to aeronomy, COSPAR Technique Manual Series 7, 1-107, Bibcode: 1978cosp.conf... .D, 1978.

Detwiler, C. R., Purcell, J. D., and Tousey, R.: The extreme ultraviolet spectrum of the sun, Mem. Soc. Roy. Sc. Liege 5, Ser. IV, 254-267, 1961.

Donnelly, R. F.: Foukal (Ed.) Solar Radiative Output Variation, Cambridge Research and Instrumentation Inc., Cambridge, Mass., 139-164, ISBN: 0387376259, 1987.

Eparvier, F. G., Jones, A. R., Chamberlin, P. C., Woods, T. N., McClintock, W. E., and Snow, M.: The Extreme Ultraviolet Sensor (EUVS) for GOES-R, SPIE Proc., 7438-19, Bibcode: 2009SPIE.7438E..02E, 2009.

Evans, J. S., Strickland, D. J., Woo, W. K., McMullin, D. R., Plunkett, S. P., Viereck, R. A., Hill, S. M., Woods, T. N., and Eparvier, F. G.: Early Observations by the GOES-13 Solar Extreme Ultraviolet Sensor (EUVS), Solar Phys. 272, 71-115, doi:10.1007/s11207-009-9491-x, 2010.

Fischer, F. and Schmidtke, G.: Rocket-born auroral measurements, J. Geophys. Res. 85, 4716-4720, doi:10.1029/JA085iA09p04716, 1980.
Fischer, F., Stasek, G., and Schmidtke, G.: Identification of auroral EUV emissions, Geophys. Res. Lett. 7, 1003-1006, doi:10.1029/GL007i011p01003, 1980.

Hall, L. A. and Hinteregger, H. E.: Solar radiation in the extreme ultraviolet and its variation with solar rotation, J. Geophys. Res. V., 75, 6959-6965, doi:10.1029/JA075i034p06959, 1970.

Heroux, L. and Hinteregger, H. E.: Resistance Strip Magnetic Photomultiplier for the Extreme Ultraviolet, Rev. Sci. Instrum., 31, 280—286, doi:10.1063/1.1716957, 1960.

Hinteregger, H. E.: Solar XUV spectrum from 310 A to 55 A, in Space Astrophysics, Liller Ed., McGraw Hill Publ., 34-95, ISBN: 1179436148, 1961a.

Hinteregger, H. E.: Rocket spectra of the chromosphere, Proceedings of the Symposium The Solar Spectrum, Utrecht, Mem. Soc. Roy. Sc. Liege 5, Ser. IV, 179-212, 1961b.

Hinteregger, H. E.: Rocket spectra of the chromosphere, Astrophysics and Space Science Library 2, 179-205, Bibcode: 1965ASSL....1..179H, 1965.

Hinteregger, H. E.: Representations of solar EUV fluxes for aeronomical applications, Adv. Space Res. 1, 39-52, Bibcode: 1981meth.conf...39H, 1981.

Hinteregger, H. E., Hall, L. A., and Schweizer, W.: Solar XUV spectrum of March, 1964, Astrophys. J. 142, 13-15, doi:10.1086/147921, 1964.

Hinteregger, H. E., Schmidtke, G., and Hall, L. A.: Solar XUV radiation and neutral particle distribution in July 1963 thermosphere, Space Res. V, 1175-1190, 1965.

Hinteregger, H. E., Fukui, K., and Gilson, G. R.: Observational, reference and model data on solar EUV, from measurements on AE-E, Geophys. Res. Lett. 8, 1147-1150, doi:10.1029/GL008i011p01147, 1981.

Hochedez, J.-F., Schmutz, W., Nesladek, M., Stockman, Y., Schühle, U., BenMoussa,, A., Koller, S., Haenen, K., Berghmans, D., Defise, J.-M., Halain, J.-P., Theissen, A., Delouille, V., Slemzin, V., Gillota,y D., Fussen, D., Dominique, M., Vanhellemont, F., McMullin, D., Kretschmar, M., Mitrofanov, A., Nicula, B., Wauters, L., Roth, H., Rozanov, E., Rüedi, I., Wehrli, C., Amano, H., Van der Linden, R., Zhukov, A., Clette, F., Koizumi, S., Mortet, V., Remes, Z., Petersen, R., D'Olieslaeger, M., Roggen, J., and Rochus, P.: LYRA: a Solar UV radiometer on Proba2, Adv. Space Res. 37, 303-312, doi: 10.1016/j.asr.2005.10.041, 2006.

Hsieh, K. C., Keppler, E., and Schmidtke. G.: Forward photoemission from thin carbon foils, Appl. Opt., 18, 3732-3733, doi:10.1364/AO.18.003732, 1979.

Ivanov-Kholodny, G. S.: Solar EUV quasi-biannual variations, Phys. Chem. Earth C, 25, 433-435, doi:10.1016/S14641917(00)00051-9, 2000.

Johnson, F. S., Malitson, H. H., Purcell, J. D., and Tousey, R.: Emission Lines in the Extreme Ultraviolet Spectrum of the Sun, Astrophys. J., 127, 80—95, doi:10.1086/146441, 1958.

Judge, D. L., Ogawa, H. S., McMullin, D. R., and Gangopadhyay, P. : The SoHO CELIAS/SEM data base, Phys. Chem. Earth C 25, 417-420, doi:10.1016/S1464-1917(00)00047-7, 2000.

Kazachevskaya, T. V. and Katyushina V. V.: Variations in the $\mathrm{H}$ Ly@a Intensity in Solar Activity Cycles from Measurements Onboard Satellites and Rockets, Phys. Chem. Earth C, 25, 425-427, doi:10.1016/S1464-1917(00)00049-0, 2000. 
Kiepenheuer, K. O.: On the relations between ionosphere, sunspots and solar corona, Ann. Astrophys. V., 8, 210-220, 1945.

Kocharov, G. E., Charikov Yu. E., Lazutkov V. P., Matveev G. A., Nitsora Yu. N., Savchenko M. I., and Skorodumov D. V.: Phys. Chem. Earth C, 25, 405-406, doi:10.1016/S14641917(00)00043-X, 2000.

Kotov, Yu. D., Kochemasov, A. V., Glyanenko, A. S., Yurov, V. N., and Arkhangelsky, A. I.: PHOKA experiment: Description of the equipment and first results, Solar System Res. 45, 153-161, doi:10.1134/S0038094611020109, 2011.

Lean, J.: Solar ultraviolet irradiance variations: A review, Geophys. Res. 92, 839-868, doi:10.1029/JD092iD01p00839, 1987.

Lean, J.: Variations in the sun's radiative output, Rev. Geophys, 29, 505-535, doi:10.1029/91RG01895, 1991.

Lean, J.: The Sun's Variable Radiation and Its Relevance For Earth, Ann. Rev. Astron, Astrophys. 35, 33-67, doi:10.1146/annurev.astro.35.1.33, 1997.

Meehl, G. A., Tebaldi, C., Walton, G., Easterling, D., and McDaniel, L.: Relative increase in record high maximum temperatures compared to record low minimum temperatures in the US, Geophys. Res. Lett., 36, L23701, 23 p., doi:10.1029/2009GL040736, 2009.

Meier, R. R.: Ultraviolet spectroscopy and remote sensing of the upper atmosphere, Space Science Rev. 58, 1-185, doi:10.1007/BF01206000, 1991.

Mikhailov, A. V.: Aeronomic Estimates of Solar EUV Fluxes Using Incoherent Scatter Observations, Phys. Chem. Earth C, 25, 505509, doi:10.1016/S1464-1917(00)00066-0, 2000.

Neupert, W. M., Behring W. E., and Lindsay W. C.: The energy distribution in the solar EUV spectrum and abundance of elements in the solar atmosphere, Space Res. IV, 719-726, 1964.

Nusinov, A. A.: Ionosphere as a natural detector for investigations of solar EUV flux variations, Adv. Space Res. 37, 426-432, doi:10.1016/j.asr.2005.12.001, 2006.

Nusinov, A. A., Kazachevskaya T. V., and Katyushina V. V.: A flux of EUV emission measured on-board the "CORONAS" artificial satellites near minimum and maximum of the 23rd cycle of solar activity, Adv. Space Res., 37, 246-252, doi:10.1016/j.asr.2005.03.034, 2006.

Pap, J. M., Fröhlich, C., Hudson, H. S., and Solanki, S. K. (Eds): The Sun as a Variable Star: Solar and Stellar Irradiance Variations, Cambridge University Press, Cambridge, 1-355, ISBN 0 521420067 H/b, 1994.

Pietenpol, W. B., Rense, W. A., Walz, F. C., Stacey, D. S., and Jackson, J. M.: Lyman Alpha-Line Photographed in the Sun's Spectrum, Phys. Rev. 90, 156-156, doi:10.1103/PhysRev.90.156, 1953.

Pflug, K., Kotov, Yu. D., and Schmidtke, G.: EUV-PHOKA measurements of solar spectral irradiance variations in the EUV/XUV region, J. Moscow Phys. Soc. 6, 337-346, 1996.

Regener, E.: http:vorarlberg.naturfreunde.at/Berichte/detail/30008/, 1932.

Regener, E.: http:de.wikipedia.org/wiki/Regener-Tonne, 1942.

Rense, W. A.: Intensity of Lyman-Alpha Line in the Solar Spectrum, Phys. Rev. 91, 299-302, doi:10.1103/PhysRev.91.299, 1953.

Richards, P. G. and Torr, D. G.: An investigation of the consistency of the ionospheric measurements of the photoelectron flux and solar EUV flux, J. Geophys. Res. 89, 5625-635, doi:10.1029/JA089iA07p05625, 1984.
Rottman, G. J.: Solar Radiative Output Variation, edited by: P. Foukal, Cambridge Research and Instrumentation Inc. Boulder, 71-85, ISBN: 0387376259, 1987.

Saha, N.: On the action of ultra-violet sunlight upon the upper atmosphere, Proc. Roy. Soc. A160, 155, 254-262, 1937.

Sawyer, G. A., Bearden, A. J. Henins, I., Jahoda, F. C., and Ribe, F. L.: X-Ray Crystal Spectroscopy of a Theta-Pinch Plasma in the Region 15-25 ̊, Phys. Rev., 131, 1891-1897, doi:10.1103/PhysRev.131.1891, 1963

Schmidtke, G.: Soller-Blendensysteme als Kollimatoren und Beugungsfilter, Zeitschrift angew. Phys. 25, 314-318, 1968.

Schmidtke, G.: Diffraction filters in XUV spectroscopy, Appl. Opt., 9, 447-450, doi:10.1364/AO.9.000447, 1970.

Schmidtke, G.: New techniques for differential pumping systems, Rev. Scientific Instruments 42, 1431-1433, doi:10.1063/1.1684899, 1971.

Schmidtke, G.: J. Phase lag of atomic density increase in the thermosphere, Geophys. Res., 80, 1367-1369, doi:10.1029/JA080i010p01367, 1975.

Schmidtke, G.: EUV indices for solar-terrestrial relations, Geophys. Res. Lett., 3, 573-576, doi:10.1029/GL003i010p00573, 1976a.

Schmidtke, G.: Solar XUV measurements with in-flight calibration needed for aeronomy, Space Res. XVI, 229-233, doi:10.1029/GL003i010p00573, 1976 b.

Schmidtke, G.: Infrared-XUV telescope for multipurpose applications, Appl. Opt., 16, 244-247, doi:10.1364/AO.16.000244, 1977.

Schmidtke, G.: Todays knowledge of the solar EUV output and the future needs for more accurate measurements for aeronomy, Planet. Space Sci., 26, 347-353, doi:10.1016/00320633(78)90118-6, 1978.

Schmidtke, G.: Modelling of the solar extreme ultraviolet irradiance for aeronomic applicatians, in Encyclopedia of Physics V, XLIX/7, Geophysics V- III/VII, 1-55, ISBN: 3-540-11425-4, 1984.

Schmidtke, G.: Photoabsorption Cross Sections: Effect of 'Radiation Hardening', Phys. Chem. Earth (C) 25, 583-585, doi:10.1016/S1464-1917(00)00081-7, 2000a.

Schmidtke, G.: TIGER: A Program for Thermospheric-Ionospheric Geospheric Research, Phys. Chem. Earth (C) 25, 363 p., doi:10.1016/S1464-1917(00)00033-7, 2000b.

Schmidtke, G., and Schweizer, W.: Sonnenbeobachtung und forschung mit Raketen, Forschungsbericht BMBW-FB W 72-27, 1-24, 1972.

Schmidtke, G., Baker, K. D., Stasek, G., Wita, C., and Seidl, P.: Rocket-borne EUV-visible emission measurements, Adv. Space Res. 2, 103-106, doi:10.1016/0273-1177(82)90371-4, 1983.

Schmidtke, G., Brunner, R., Eberhard, D., Halford, B., Klocke, U., Knothe, M., Konz, W., Riedel, W.-J., and Wolf, H.:-SOL-ACES: Auto-calibrating EUV/UV spectrometers for measurements onboard the International Space Station, Adv. Space Res. 37, 273282, doi:10.1016/j.asr.2005.01.112, 2006a.

Schmidtke, G., Doll, H. G., and Wita, C.: Measuring of solar EUV/UV radiation of the steeply rising solar cycle 22 during the San Marco 5 mission and proposed instrumentation to achieve high radiometric accuracy., Adv. Space Res. 13, 221246, doi:10.1016/0273-1177(93)90073-K, 1993.

Schmidtke, G., Doll, H. G., Wita, C., and Chakrabarti, S.: Solar EUV/UV and equatorial airglow measurements from 
San Marco-5, J. Atmos. Terr. Phys., 53, 781-785, Bibcode: 1991JATP...53..781S, 1991.

Schmidtke, G., Eparvier, F.-G., Solomon, S.-C., Tobiska, W.-K., and Woods, T.-N.: The TIGER (thermospheric-ionospheric geospheric research) program: Introduction, Adv. Space Res. 37, 2, 194_198, doi:10.1016/j.asr.2005.02.088, 2006b.

Schmidtke, G., Henneberg, P., Hager, K.-H., Busch, F., and Reinhardt, D.: Parabolic telescope and spectrometer combination, Applied Optics 19, 1822-1832, doi:10.1364/AO.19.001822, 1980.

Schmidtke, G., Knothe, M., and Heidinger, F.: Magnetic electron multipliers: efficiency changes, Appl. Opt., 14, 1645-1648, doi:10.1364/AO.14.001645, 1975.

Schmidtke, G., Nikutowski, B., Jacobi, Ch., Brunner, R., Erhardt, Ch., Knecht, S., Scherle, J., and Schlagenhauf, J.: Solar EUV Irradiance Measurements by the Auto-Calibrating EUV Spectrometers (SolACES) Aboard the International Space Station (ISS), Sol. Phys., 289, 5, 1863-1883, doi:10.1007/s11207-013-0430-5, 2014.

Schmidtke, G., Schweizer, W., and Knothe, M.: The AEROS-EUV Spectrometer, J. Geophys., 40, 577-584, 1974.

Schmidtke, G., Seidl, P., and Wita, C: Airglow-solar spectrometer instrument (20-700 nm) aboard the San Marco D/L satellite, Appl. Opt., 24, 3206-3213, doi:10.1364/AO.24.003206, 1985.

Schmidtke, G., Stasek, G., Wita, C., Seidl, P., and Baker, K. D.: Rocket-borne EUV-visible emission measurements, J. Atmosph. Terr. Phys., 47, 147-158, Bibcode: 1985JATP...47..147S, 1985.

Schmidtke, G., Tobiska, W. K., and Winningham, D.: TIGERprogram for thermospheric-ionospheric geospheric research. Long-term measurement of solar EUV/UV fluxes for thermospheric-ionospheric (T/I) modelling and for space weather investigations, Adv. Space Res., 29, 1553-1559, doi:10.1016/S0273-1177(02)00210-7, 2002.

Schmidtke, G., Woods, T. N., Worden, J., Rottman, G. J., Doll, H. G., and Wita, C.: Solar EUV irradiance from the San Marco ASSI - A reference spectrum, Geophys. Res. Lett., 19, 2175178, doi:10.1029/92GL02183, 1992.

Schweizer, W. and Schmidtke G.: High-resolution extremeultraviolet solar spectrum recorded with a diffraction-filter spectrograph, Astrophys. J., 169, L 27-L29, doi:10.1086/180807, 1971.

Seidl, P., Schmidtke, G., and Acton, L. W.: Diffraction properties of hydrogen-phthalate-crystals in the 0.1-2-nm region, Appl. Opt., 16, 578-581, doi:10.1364/AO.16.000578, 1977.

Siskind, D. E., Barth, C. A., and Cleary, D. D.: The possible effect of solar soft $\mathrm{X}$ rays on thermospheric nitric oxide, J. Geophys. Res., 95, 4311-4317, doi:10.1029/JA095iA04p04311, 1990.

Solomon, S. C., Bailey S. M., and Woods T. N.: Effect of solar soft X-rays on the lower ionosphere, Geophys. Res. Lett., 28, 21492152, doi:10.1029/2001GL012866, 2001.

Strauss, K.: Entwicklung eines Spectrometers zur Messung von $\mathrm{CO}_{2}$-Emissionen, Diplomarbeit Albert Universität Freiburg am Fraunhofer Institut für Physikalische Messtechnik, 1980.

Theile, B., Boström R., Dumbs A., Grossmann K. U., Krankowsky D., Lämmerzahl P., Marklund G., Neske E., Schmidtke G., and Wilhelm, K.: In situ measurements of heating parameters in the auroral ionosphere, Planet. Space Sci., 29, 455-468, doi:10.1016/0032-0633(81)90089-1, 1981.
Thuillier, G., Floyd, L. E., Woods, T. N., Cebula, R., Hilsenrath, E., Hersè, M., and Labs, D: Solar irradiance reference spectra for two solar active levels, Adv. Space Res., 34, 256-261, doi:10.1016/j.asr.2002.12.004, 2004.

Thuillier, G., Floyd., L., Woods, T.-N., Cebula, R., Hilsenrath, E., Hersé, M., and Labs, D.: Solar Irradiance Reference Spectra, Solar Variability and its Effect on Climate, AGU monograph 141, edited by: Pap, J. and Fox, P., 171-194, Bibcode: 2004GMS...141..171T, 2004.

Timothy, A. F. and Timothy J. G.: Long-term intensity variations in the solar helium II Lyman alpha line, J. Geophys. Res., 75, 6950-6958, doi:10.1029/JA075i034p06950, 1979.

Tobiska, W. K., Chakrabarti, S., Schmidtke, G., and Doll, H. G.: Comparative solar EUV flux for the San Marco ASSI, Adv. Space Res., 13, 255-259, doi:10.1016/0273-1177(93)90022-4, 1993.

Tobiska, W. K., Gladstone, G. R., Chakrabarti, S., Shepherd, M. G., McConnel, J. C., Link, R., Schmidtke, G., and Stasek, G.: FUVVisible photometric imaging of aurorae , J. Geophys. Res., 98, 17525-17536, doi:10.1029/92JA02561, 1993.

Tobiska, W. K.: Recent solar extreme ultraviolet irradiance observations and modelling: A review, J. Geophys. Res., 98, 18879 18893, doi:10.1029/93JA01943, 1993.

Tousey, R.: The extreme ultraviolet spectrum of the sun, Space Science Rev., 2, 3-69, doi:10.1007/BF00174027, 1963.

Warren, H. P.: A Solar Minimum Irradiance Spectrum for Wavelengths below $1200 \AA$ Å, Astrophys. J. Suppl., 157, 147-173, doi:10.1086/427171, 2005.

White, O. R. (Ed.): The solar output and its variation, Colorado Ass. Univ. Press, Boulder, ISBN: 0-87180-07105, 1977.

Woods, T. N.: Recent advances in observations and modeling of the solar ultraviolet and X-ray spectral irradiance, Adv. Space Res., 42, 895-902, doi:10.1016/j.asr.2007.09.026, 2008.

Woods, T. N. and Eparvier, F. G.: Solar ultraviolet variability during the TIMED mission, Adv. Space Res., 37, 219-224, doi:10.1016/j.asr.2004.10.006, 2006.

Woods, T. N. and Rottman, G. J.: Solar EUV irradiance derived from a sounding rocket experiment on 10 November 1988, J. Geophys. Res., 95, 6277-6236, doi:10.1029/JA095iA05p06227, 1990.

Woods, T., Acton, L. W., Bailey, S., Eparvier, F., Garcia, H., Judge, D., Lean, J., McMullin, D., Schmidtke, G., Solomon, S. C., Tobiska, W. K., and Warren, H. P.: Solar Variability and Its Effect on Climate, edited by: Pap, J., Fröhlich, C., Hudson, H., Kuhn, J. McCormack, J., North, G., Sprig, W., and Wu, S. T.: Solar Extreme Ultraviolet and X-ray Irradiance Variations, Geophys. Monograph series 141, Wash. DC., 127-140, Bibcode: 2004GMS...141..127W, 2004.

Woods, T. N., Bailey, S. M., Eparvier, F. G., Lawrence, G., Lean, J., McClintock, B., Roble, R., Rottman, G. J., Solomon, S. C., Tobiska, W. K., and White, O. R.: TIMED Solar EUV experiment, Phys. Chem. Earth C, 25, 393-96, doi:10.1016/S14641917(00)00040-4, 2000.

Woods, T.-N., Eparvier, F.-G., Hock, R., Jones, A. R., Woodraska, D., Judge, D., Didkovsky, L., Lean, J., Mariska, J., Warren, H., McMullin, D., Chamberlin, P., Berthiaume, G., Bailey, S., Fuller-Rowell, T., Sojka, J., Tobiska, W.-K., and Viereck, R.: Extreme Ultraviolet Experiment (EVE) on the Solar Dy- 
namic Observatory (SDO), Sol. Phys., 275, 1-2, 115-144, doi:10.1007/s11207-009-9487-6, 2010.

Woods, T. N., Francis, G. E., Bailey, S. M., Chamberlin, P. C., Lean, J., Rottman, G. J., Solomon, S. C., Tobiska, W. K., and Woodraska, D. L.: Solar EUV Experiment (SEE): Mission overview and first results, J. Geophys. Res., 110, A01312, 1-24, doi:10.1029/2004JA010765, 2005.

Woods, T.- N., Chamberlin, P. C., Harder, J. W., Hock, R., A., Snow, M., Eparvier, F. G., Fontenla, J., McClintock, W. E., and Richard, E. C.: Solar Irradiance Reference Spectra (SIRS) for the 2008 Whole Heliosphere Interval (WHI), Geophys. Res. Lett., 36, 15, L01101, doi:10.1029/2008GL036373, 2009.
Worden, J., Woods, T. N., Rottman, G. J., Schmidtke, G., Tai, H., Doll, H. G., and Solomon, S. C.: Calibration of the San Marco airglow-solar spectrometer instrument in the extreme ultraviolet, Opt. Eng., 35, 554-563, doi:10.1117/1.601037, 1996.

Worden, J., and Woods, T. N.: Private communication, 1996.

Unglaub, C., Jacobi, Ch., Schmidtke, G., Nikutowski, B., and Brunner R.: EUV-TEC proxy to describe ionospheric variability using satellite-borne solar EUV measurements: First results, Adv. Space Res., 47, 1578-1584, doi:10.1016/j.asr.2010.12.014, 2011.

Unglaub, C., Jacobi, Ch., Schmidtke, G., Nikutowski, B., and Brunner, R.: Proxies to describe ionospheric variability and heating rates of the upper atmosphere, Wiss. Mitt. Inst. f. Meteorol. Univ. Leipzig, 48, 45-54, 2012. 